\title{
Fish, amphibian and reptilian faunas from latest Oligocene to middle Miocene localities from Central Turkey
}

\author{
Davit Vasilyan $^{1,2}$ (1) $\cdot$ Zbyněk Roček $^{3} \cdot$ Anna Ayvazyan $^{4} \cdot$ Leon Claessens $s^{5,6}$
}

\begin{abstract}
In this paper, we describe ectothermic vertebrate assemblages from the Karg1 1, Karg1 2, Karg1 3, Harami1, Harami 3, Hanc1l1, Keseköy, Çandır and Bağiçi localities in Turkey. The ages of these localities range from the latest Oligocene to the middle Miocene. The preserved non-mammalian fauna of the studied localities includes fishes (Luciobarbus sp., Barbus sp., Luciobarbus vel Barbus sp., aff. Capoeta sp., Barbini indet., Leuciscus sp.), anurans (Bufonidae indet. (? Pseudepidalea sp.), Pelobatidae indet., Latonia sp., Palaeobatrachidae indet.), caudates (Salamandra sp.), lizards (Pseudopus sp., Lacertidae indet. 1, Lacertidae indet. 2, Lacertidae indet. 3, Lacertidae indet. 4, Blanidae indet. (?Blanus sp.)), snakes (Albaneryx sp., Erycinae indet.) and crocodiles (Crocodylia indet.). Here, we describe, for the first time, the fossil occurrences of the genera Salamandra, Albaneryx and Pseudopus from Anatolia, as well as the first fossil representative of the clade of the Western Asian lizards (Lacertidae indet. 3). Our study provides the earliest known fossil occurrences of the genera Luciobarbus, Barbus, Pseudopus and Albaneryx. Palaeobiogeographic relationships of each studied group are discussed and compared with the European and Asiatic records. A tentative palaeoenvironmental reconstruction is provided for each locality.
\end{abstract}

Keywords Fishes · Amphibians · Reptiles · Turkey $\cdot$ Latest Oligocene_middle Miocene $\cdot$ Palaeobiogeography

\section{Introduction}

Multiple publications dealing with assemblages of small and large mammals have summarised the rich fossil record of these groups in Anatolia (Wang et al. 2013; Marković et al. 2018). In contrast, fossil fishes, amphibians and reptiles from Anatolia have not been yet thoroughly investigated. In order to understand migrations of vertebrates between Asia and Europe in the late Paleogene and early Neogene (Rössner and Heissig 1999; De Bruijn et al. 2013), it is essential to have an understanding of the fossil record of Anatolia, which likely lays on the migration route between Europe and Asia for many species.

A brief overview (Böhme et al. 2003), based on disarticulated fossil material, stood at the basis for a review of the possible relationships between the Anatolian Neogene freshwater fish fauna and those of Europe and Asia. Similarities of the Anatolian fauna were recognised: (1) with that from the central Europe for the most part of the early Miocene; (2) with those from Central Asia for the late early Miocene and early middle Miocene. Few early Miocene localities, e.g. Ağaöz (Paicheler et al. 1978) and AlpagutDodurga (Rückert-Ülkümen 1998), provided articulated 
skeletons of cyprinid fishes. However, this material does not allow observation of the morphology of the pharyngeal teeth, or association to postcranial and other cranial elements.

Hitherto published early-to-middle Miocene amphibians of Anatolia include Salamandridae indet., Pelobates, Pelophylax, Rana (Paicheler et al. 1978), Palaeobatrachidae indet and Bufotes (=Pseudepidalea) (Claessens 1997) (Table 1).

Recently, Vasilyan et al. (2017) analysed the European and western Asian amphibian and reptilian Neogene record, suggesting that Anatolia played an important role in the dispersal of some amphibians and reptilian lineages, especially during the early Miocene. Also Claessens (1997) suggested Anatolia to be a migration route for the genus Bufotes (=Pseudepidalea) for the migrations from Asia to Europe. Around a dozen publications have studied the nonmammalian vertebrate faunas from Anatolia (Table 1). Among them, the recent study by Čerňanský et al. (2017) suggested relations of Ophisaurus sp. from the Karg1 2 locality (Oligo-Miocene boundary) with Ophisaurus from the middle Miocene of Kazakhstan (Vasilyan et al. 2016).

Further ectothermic vertebrates, such as the lizards Pseudopus and Varanus, have their earliest appearances in Europe during the early Miocene, around 18-17 Ma, during the so-called Proboscidean Datum Event. As it has been documented for different mammals, they arrived in Europe from Anatolia (Rössner and Heissig 1999). Similar migrations during the early Miocene, however, have not been documented for other vertebrate groups. Only the discovery of the genus Bavarioboa in the eastern Anatolia (Szyndlar and Hoşgör 2013) provided a strong evidence of biogeographic connection of the European and southwestern Asian ophidian faunas at the Oligocene/Miocene boundary.

Summarising the known Cenozoic fossil record of Anatolia in the context of those from Europe and Asia, it holds significant potential for resolution of numerous palaeogeographic questions about the origin of some European fish, amphibian and reptile groups as well as for shedding light on timing of migration events for fish, amphibians and reptiles between Europe, Asia and Africa.

In this study, we present (1) new information on ectothermic vertebrates, recovered from localities previously studied for small mammals; (2) the palaeobiogeographic context on these finds; and (3) tentative palaeoenvironmental interpretations of the localities.

\section{Materials and methods}

The fossil material described in this study originates from nine latest Oligocene to middle Miocene localities (Karg1 1, Karg1 2, Kargı 3, Harami 1, Harami 3, Keseköy, Çandır, Hancılı, Bağiçi). Part of the material has been studied and discussed by one of the authors in his unpublished Master's thesis
(Claessens 1996). The depositional environments, small mammal faunas, biochronologic correlations and absolute ages of the localities have been discussed and summarised in Claessens (1996), Krijgsman et al. (1996), Kaymekci (2000), Krijgsman (2003), De Bruijn et al. (2013) and Čerňanský et al. (2017) (Fig. 1). The different tooth and dorsal spine morphologies for the studied barbin fishes are indicated with a d (e.g. d1, d2) and s (e.g. s1, s2) respectively.

The studied fossil material has been collected from the fossiliferous horizons by screen washing of the sediment samples and picking the sediment residue. The described material is temporarily stored in the palaeontological collection of the University Utrecht (UU) and will be returned to the General directorate of mineral research and exploration (MTA) in Ankara. The material has been photographed by the digital microscope, Leica DVM5000 (Tübingen, Germany), the electronic microscope FEI XL 30 Sirion and Canon EOS 50D camera.

The extant comparison material of fishes is stored at the osteological collection of the National Museum of Natural Sciences of Madrid (MNCN) and at the Bavarian State Collection for Anthropology and Palaeoanatomy, Munich (SNSB). The pharyngeal bones of the extant Barbus and Luciobarbus species are scanned using X-ray computed tomography $(\mu \mathrm{CT})$. MicroCT images were taken using the microtomography systems NIKON XT H 160 at the scanning electron microscopy, analytic laboratories of the MNCN. The scan settings of the pharyngeal bones are introduced in Supplementary Material 1. The tomographic reconstruction was performed using Avizo 9.0 software at Tübingen University.

\section{Systematic palaeontology (level 1)}

Class Actinopterygii Cope, 1887

Clade Teleosteomorpha Arratia, 2000

Order Cypriniformes Bleeker, 1859

Family Cyprinidae Rafinesque, 1815

Subfamily Cyprininae (Rafinesque, 1815) (sensu Yang et al., 2015)

Tribe Barbini Bleeker, 1859 (sensu Yang et al., 2015)

Genus Luciobarbus Heckel, 1843 (sensu Yang et al., 2015)

Fig. 2(a-c)

Below we provide short notes on the pharyngeal dentition of the genus Luciobarbus and illustrate the teeth, using Luciobarbus longiceps (MNCN E 54), L. comizo (MNCN 69304) and L. sclateri (MNCN 69331) (Fig. 2a-c), as a framework for anatomical comparison. The pharyngeal teeth of the studied Luciobarbus species are arranged on the pharyngeal bone in three rows. The first (a) row contains four teeth, the second (b) three and the third row (c) two teeth. 


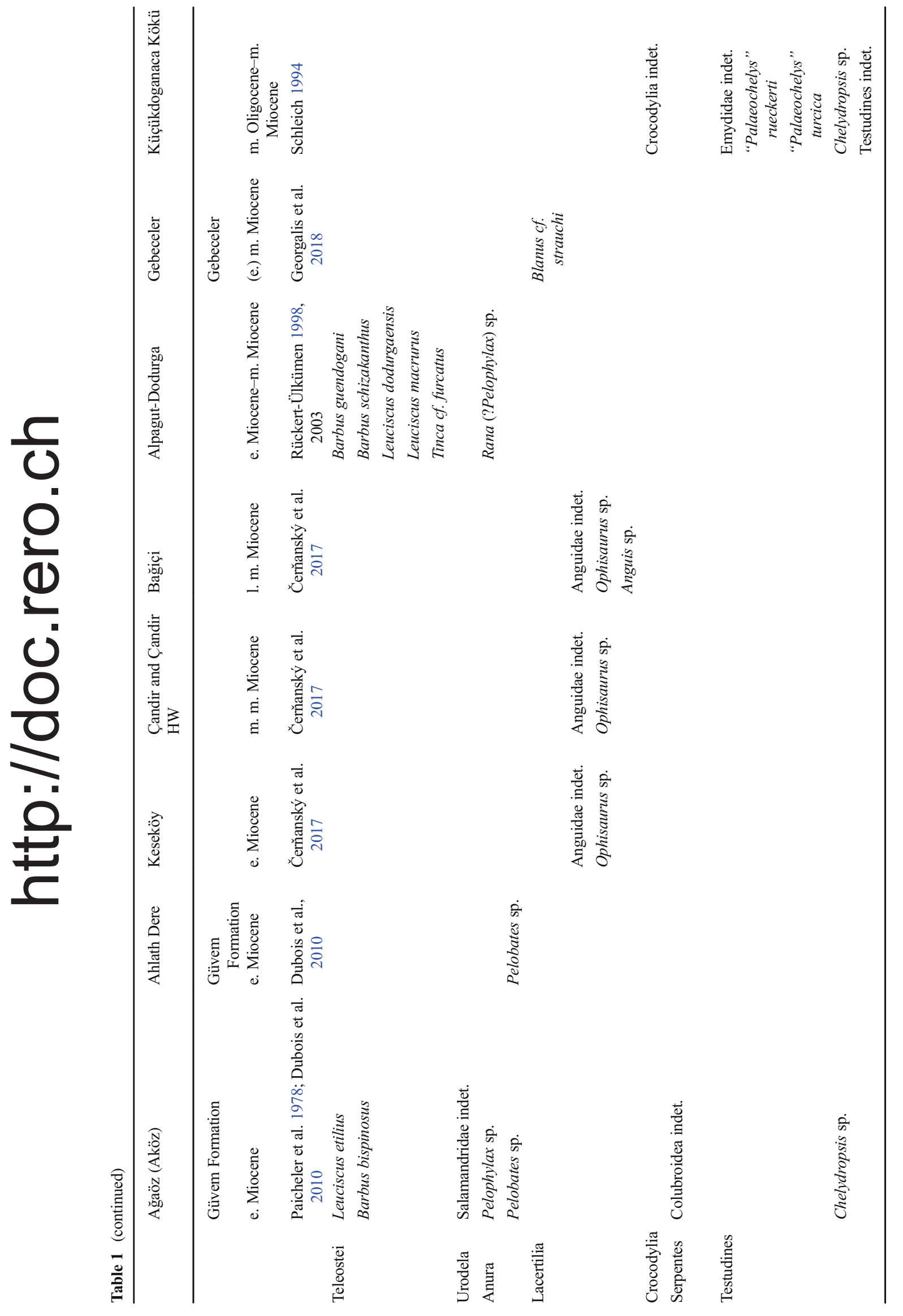




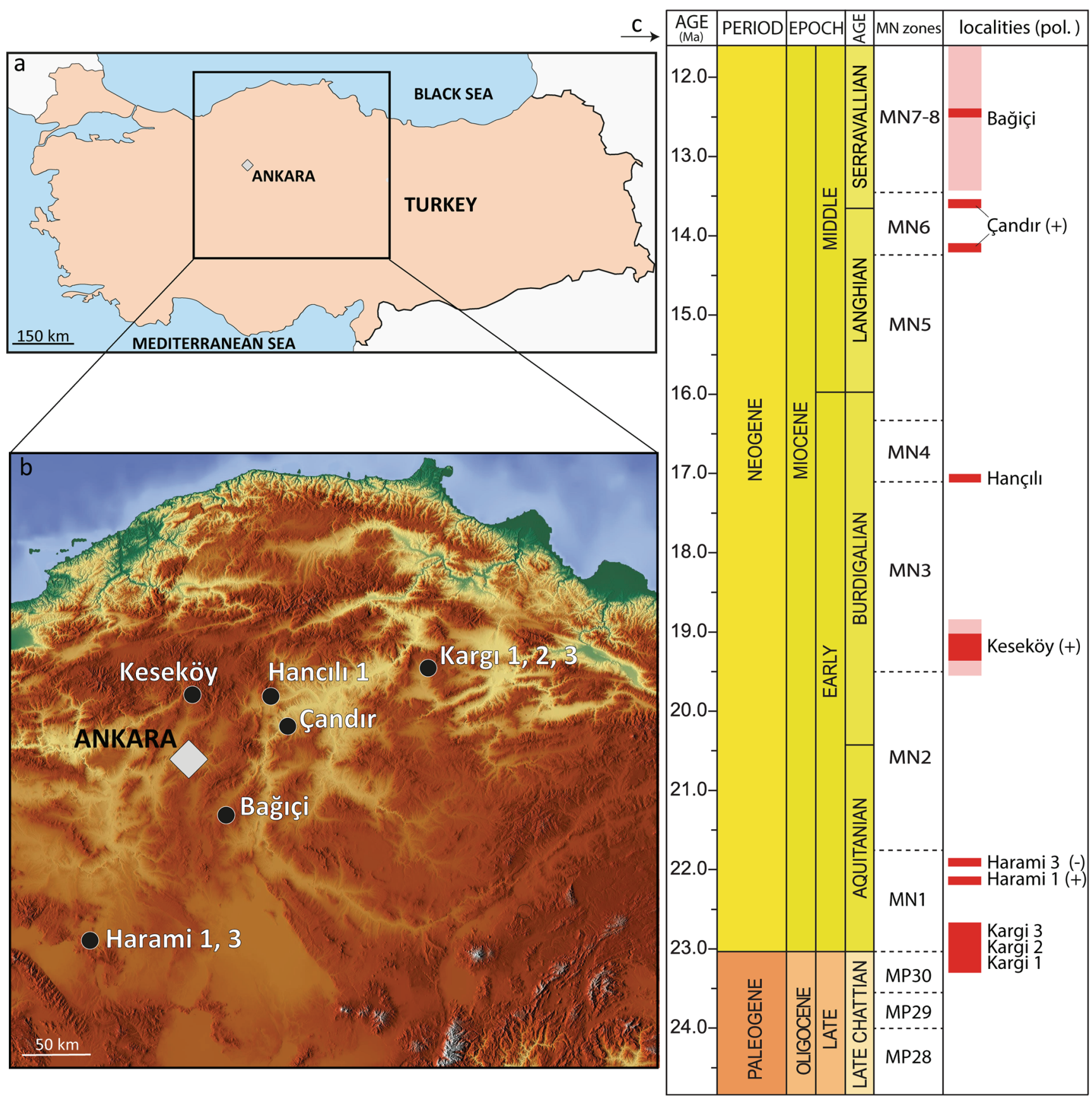

Fig. 1 a an overview map of Turkey and $\mathbf{b}$ geographic locations of the studied localities on a topographic map. c Stratigraphic chart with the studied fossil localities. The + and - in the brackets indicate

The pharyngeal teeth of the first row (a2-a5) are larger than those in the other two rows (since the al tooth in the studied species is reduced (absent), the first tooth in the first (main) row is the $\mathrm{a} 2$ tooth) (Fig. 2(a-c)). The tooth at the a2 position is molariform with a small "hook" ( $L$. longiceps and L. sclateri) or has flat surface (L. comizo). The a3 tooth is the second large tooth of the main row after the a2. The tooth foot is longer than the crown; the foot-crown border is welldistinguishable. The crown is posteriorly convex. The correspondingly the normal or reverse polarity patterns of the fossiliferous layer according to Krijgsman et al. (1996) and Krijgsman (2003)

grinding surface has a C-shape with the hook on the top of it (not well-developed at the a3 of L. longiceps (Fig. 2(b)) and L. sclateri (Fig. 2(c))). The teeth at the tooth positions a4 and a5 are spoon-shaped and compressed anteroposteriorly. A hook is present at the laterodorsal corner of the tooth, projecting anteriorly over the grinding surface.

The pharyngeal teeth at the second (b1-b3) and third (c1-c2) rows are smaller than those of the first row. Within the studied three extant Luciobarbus species, the teeth of the second and 

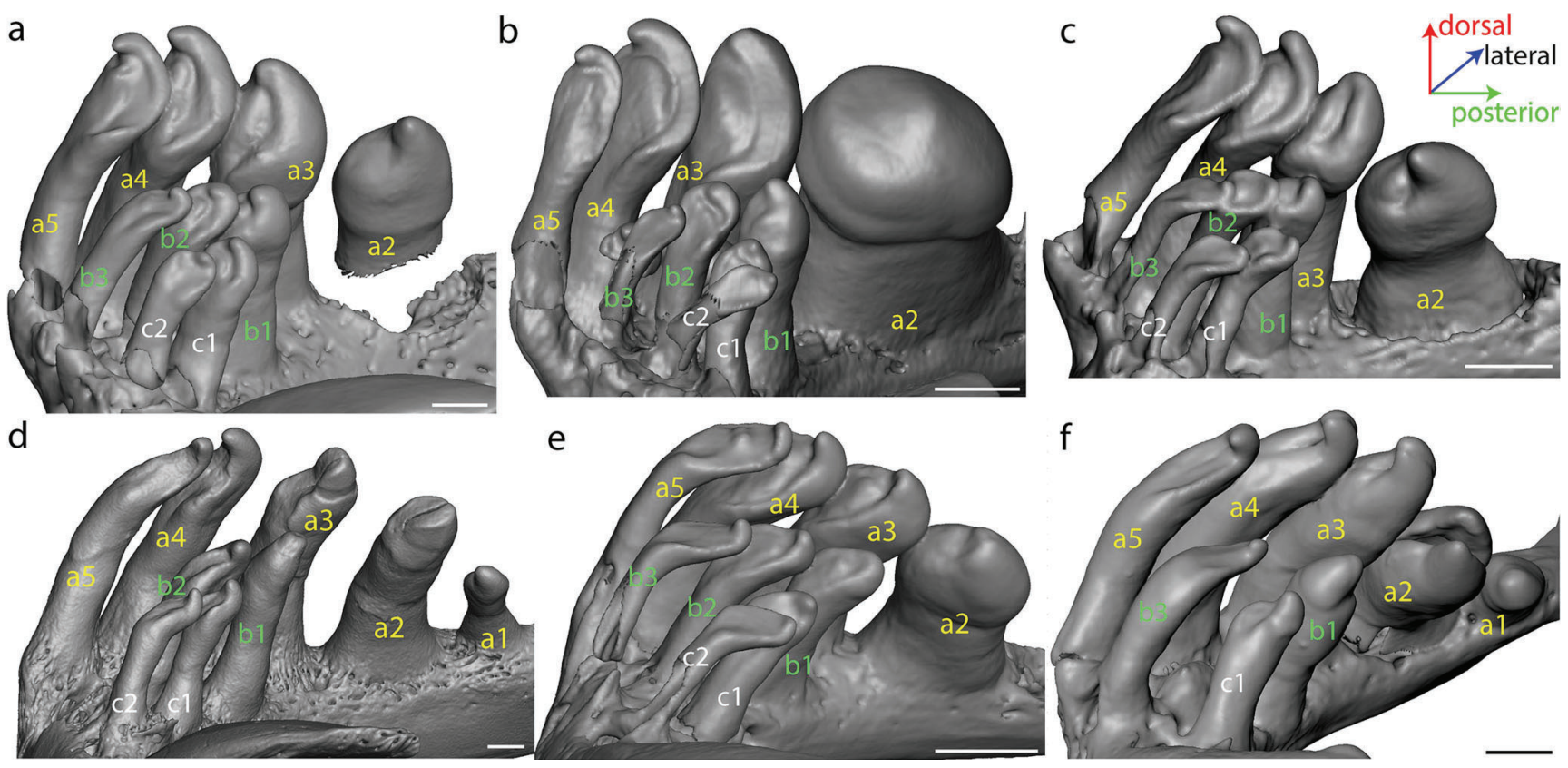

Fig. 2 Images of the 3D models of the pharyngeal bones with teeth of the Luciobarbus and Barbus species. a Luciobarbus comizo (MNCN 69304), b Luciobarbus longiceps (MNCN E 54), c Luciobarbus sclateri (MNCN 69331), d Barbus barbus (SNSB SPAM-PI-00608), e

Barbus sacratus (MNCN GUI 17), f Barbus meridonalis (MNCN 19933). The letters a, b, c correspond to the first (main), second and third row; the numbers $(1-5)$ corresponds to the tooth positions in those rows. The scale bars are equal to $1 \mathrm{~mm}$

third rows can be placed in two tooth morphogroups: (1) b1, c1 and (2) b2-b3 and c2. The teeth of the first morphogroup (b1 and $\mathrm{c} 1$ tooth positions) have a posteriorly bent rounded tooth body. The foot-crown border is well-distinguishable. In anterior view, the grinding surface ruptures slightly and possesses one or two enhancements. The grinding surface has a well-developed, anterodorsally oriented hook on its tip. The teeth of the second morphogroup (b2, b3 and c2 tooth positions) are the slender of all teeth. The tooth body widens distally and is compressed anteroposteriorly. The grinding surface opens anteriorly and has one or two enhancements. These teeth are also characterised by the presence of a hook on the top of the grinding surface. In comparison with the teeth of the first morphogroup, the grinding surface of these teeth $(b 2, b 3, c 2)$ is more expanded.

\section{Luciobarbus sp.}

Fig. 3(a-g)

Material: loc. Hancill: tooth morphology d3 - eight pharyngeal teeth (UU HAN 5304, 5305, 5334); tooth morphology d5-four pharyngeal teeth (UU HAN 5332-5333) and one pharyngeal tooth (HAR1 5300); tooth morphology d7-21 pharyngeal teeth (UU HAN 5313-5316).

\section{Description and remarks}

Tooth morphology d3: The teeth are elongate to robust, with a straight or a medially bending tooth crown (Fig. 3(f, g)). The tooth crown possesses a hook, located either at the tooth axis or lateral from it. The hook is anteriorly pointed. The grinding surface is located at the anterior surface of the tooth. It bears a moderately high longitudinal eminence ("crest"), the length of which varies depending on crown height. The lateral margins of the grinding surfaces are elevated; dorsally, the margins reduce in height at the basis of the hook, forming constrictions. A similar morphology can be observed at the $\mathrm{b} 1$ and $\mathrm{c} 1$ tooth positions of some extant Luciobarbus spp. (Fig. 2(a-c)). Tooth morphology d5: The tooth is elongate and slightly curved along its longitudinal axis and bends medially (Fig. $3(\mathrm{~d}, \mathrm{e}))$. The anterior surface of the tooth crown is concave. The grinding surface is narrow. It extends lateromedially on the tooth dorsal surface and extends ventrally, parallel to the medial margin of the tooth. The posterior margin of the tooth is significantly higher than the anterior margin. It possesses an anteriorly directed, reduced, pointy and medially oriented hook, which is located slightly lateral from the tooth centre. This tooth morphology can be found at the b2, b3 and c2 tooth positions of the recent genus Luciobarbus (Fig. 2(a-c)).

Tooth morphology d7: The tooth crown is spoon-shaped, anteroposteriorly compressed. Its anterior surface is concave (Fig. 3(a-c)). The grinding surface has a C-shape and is located on the dorsal tip of the tooth. The lateral corner of the tooth possesses an anteriorly oriented hook, which shows a different degree of development in different individuals. In teeth with more pronounced hook, the medial corner of the grinding surface extends slightly ventrally to the tooth foot. The anterior margin of the tooth (anterior wall of the grinding surface) is lower than the posterior one. It has either convex or concave 
surfaces, corresponding to the degree of tooth wear. This tooth morphology is characteristic for the genus Luciobarbus and can be found at the a4 to a5 tooth positions (Fig. 2(b)).

Genus Barbus Cuvier and Cloquet, 1816 (sensu Yang et al., 2015) Fig. 2(d-f)

The morphology of the pharyngeal dentition of the genus Barbus is described using Barbus barbus (SNSB SPAM-PI00608), B. meridonalis (MNCN 19933) and B. sacratus (MNCN GUI 17).

The pharyngeal teeth of the genus Barbus are located in three rows in the three extant species that we examined. Five teeth are present in the first (a) row, three in the second (b) and two in the third (c) row. The teeth in the first row are larger than those in the other two rows, except for the al tooth, which is small. It has a wide tooth base which narrows distally. The tooth body is compressed at the foot-crown border and the tooth crown is slightly narrower than the tooth base. The grinding surface bears a hook on its top. The second tooth of the first row (a2) has a molariform morphology, somewhat comparable to the a1 tooth. However, the a2 tooth is several times larger than the a1. The teeth from the a 3 to a5 tooth positions show a gradual transition in the tooth morphology, with robust teeth with thick crowns and a rather small grinding surface (a3) to a tooth morphology with slender teeth, narrow crown with expanded grinding surface. In all these tooth positions, the teeth are bent and possess hooks and smooth grinding surfaces, which are delimitated by a high (a3, a4) or low (a4, a5) ridge.

The tooth body of the $\mathrm{b} 1$ tooth narrows distally. The crown is robust. The tooth body bends slightly posteriorly at the footcrown border. The grinding surface opens anteriorly and possesses a hook on the top. In anterior view, a few grooves are observable on the grinding surface. The b2 tooth has a straight tooth body, whereas the tooth crown is bent posteriorly. The grinding surface terminates with the hook on the top. Anteriorly, the grinding surface is open. The morphology of the $b 3$ and c 2 teeth is similar and comparable to b2, except that the $\mathrm{b} 3$ and $\mathrm{c} 2$ teeth are more slender and heavily bend posteriorly. In addition, the grinding surfaces of $b 3$ and $c 2$ teeth are narrower than that of $\mathrm{b} 1$. The $\mathrm{c} 1$ tooth has a straight body similar to b1, but is shorter and smaller. The grinding surface has a hook on the tip and ruptures from the anterior side.

\section{Barbus sp.}

Fig. 3(h-n)

Material: Loc. Hancili: tooth morphology d4 -23 pharyngeal teeth (UU HAN 5307, 5307-1, 5308, 5309); tooth morphology d6-28 pharyngeal teeth (UU HAN 5310-5312, 5321, 5335). Loc. Harami 1: tooth morphology d6 - one pharyngeal tooth (UU HAR1 5301).
Description and remarks

Tooth morphology d6: The teeth are elongate, rather slender and bent medially. They are twisted along their longitudinal axis (Fig. 3(h-l)). The grinding surface is well-expressed, oriented and exposed anteriorly. It has a rough surface composed of longitudinally running crests. The grinding surface is encircled by a moderately high, thin margin. The lateral margin of the grinding surface can be slightly serrated. The ventral wall of this margin can be reduced in some teeth so that the grinding surface flows in the tooth foot. The tooth crown possesses an anteriorly directed pointy hook, which projects over the grinding surface. This morphology of pharyngeal teeth can be observed at the tooth positions a3-a5 and b1b3 of the extant genus Barbus (Fig. 2(d, e)).

Tooth morphology d4: The teeth are elongate, slightly bent, rather thick and robust. The tooth crown is shorter than the tooth foot (Fig. 3(m, n)). The grinding surface is less developed than in morphology d6. It is limited mostly to the apical portion of the tooth crown. The grinding surface is rather smooth, but can still possess a few uneven structures. The grinding surface is encircled mostly by high and sharp lateral walls possessing irregular margins. The ventral wall can be reduced or well-developed. Dorsally, a pointy hook is projecting over the grinding surface. The hook can be reduced or moderately developed, but never reaches the size of that in morphology d6. Its orientation varies in the available teeth from dorsally to anteriorly directed. A comparable morphology can be found at the b2 tooth position of the genus Barbus (Fig. 2(d, f)).

\section{Luciobarbus vel Barbus sp.}

Fig. 3(o-v)

Material: Loc. Hancilı: tooth morphology d1-15 pharyngeal teeth (UU HAN 5300, 5301, 5321), tooth morphology d2 - 27 pharyngeal teeth (UU HAN 5302, 5303, 5306). Dorsal fin spine morphology s 1 - seven unbranched last spine of the dorsal fin (UU HAN 5322-5324); dorsal fin spine morphology s2 - five unbranched last spine of the dorsal fin (UU HAN 5325-5328); dorsal fin spine morphology s3 - two unbranched last spine of the dorsal fin (UU HAN 5329-5330).

\section{Description and remarks}

Tooth morphology d1: The teeth are large and robust. In cross section, the teeth are either rounded or lateromedially compressed (Fig. 3(o, p)). The tooth foot is always longer than the tooth crown. The grinding surface is reduced and has an irregular surface. The margins of the grinding surface are distinct and possess uneven (serration-like) structures. The hook is moderately pointy and shows an anterodorsal orientation. This tooth morphology is characteristic for the a1 tooth position of the genus Barbus (Fig. 2(d, e)). Since this tooth 


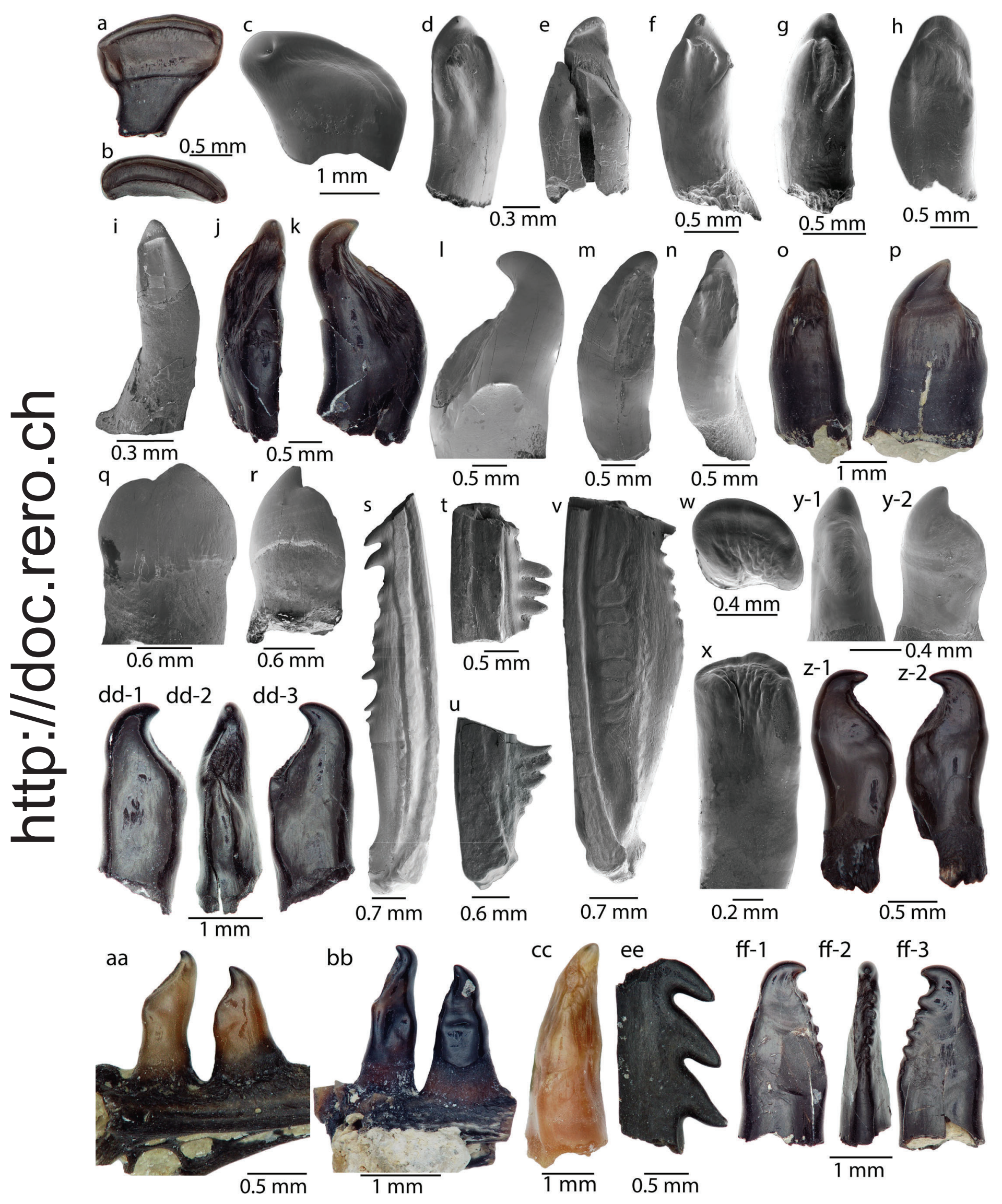


4 Fig. 3 Cyprinids from the studied localities. Luciobarbus sp., morphology d7-from Hancili, UU HAN 5315 a, b, UU HAN 5316 c; morphology d5-UU HAN 5333 d, UU HAR1 5300, loc. Hancili e; morphology d3-UU HAN 5334, loc. Hancilı f; UU HAN 5305, loc. Hancilı g. Barbus sp., morphology d6 from the loc. Harami 1, UU HAR 15301 h, loc. Hanc1l, UU HAN 5321 i, UU HAN 5311 j, k, UU HAN 5335 l; morphology d4 - UU HAN 5308 (m), UU HAN 5309 n Luciobarbus vel Barbus sp., morphology d 1 from loc. Hanc1l 1, UU HAN 5300 o, p; morphology d2, UU HAN 5303 q, UU HAN 5306 r; morphology s1, UU HAN $5324 \mathbf{s}$; morphology s2, UU HAN $5325 \mathbf{t}$, UU HAN 5326 u; morphology s3, UU HAN 5329 v. aff. Capoeta sp. from the loc. Hancili, UU HAN 5317 w, x. Barbini indet. (z-dd), UU KAR1 1304, loc. Kargi 1 y, UU KAR1 1301, loc. Kargi 1 z, UU KAR2 1301, loc. Kargi 2 aa, UU KAR2 1306, loc. Kargi 2 dd, UU KAR2 1303, loc. Kargi 2 ee, UU KE 5307, loc. Keseköy bb, UU KE 5305, loc. Keseköy cc. Leuciscus sp. from loc. Hancılı, UU HAN 5318 ff

position is not available in the studied species of the genus Luciobarbus, we prefer to place this morphology to both genera.

Tooth morphology d2: The teeth are rounded, robust, smallsized and lateromedially compressed (Fig. 3(q, r)). Both tooth foot and crown are short; in some teeth, a constriction marks the foot crown border. The tooth crown has a molariform shape. The grinding surface is either fully absent or extremely reduced. In those teeth with a grinding surface, its surface is exposed dorsally or anteriorly. The grinding surface is rough and laterally bordered by low walls. The hook is small and dorsally oriented. The described tooth morphology is characteristic of the first tooth of the main row (a2) of Barbus and Luciobarbus (Fig. 3(a, f)).

Dorsal fin spine morphology s1: The preserved spine fragments show no serration at their posterior margins (Fig. 3(s)). Slightly above the base of the spine, small posteroventrally pointed serrae appear, which become dorsally longer. The dorsal serrae are sharp and possess poorly pronounced edges. In lateral and medial views, the spine body is narrow, although in larger individuals, it can widen slightly.

Dorsal fin spine morphology s2: The spine body is slender. It possesses short posteriorly directed serrae directly at its base (Fig. 3(t, u)). Dorsally, the serrae become longer and cylindrical in shape and are sometimes curved; they point with their tip dorsally. The serrae surfaces do not possess any structures. Dorsal fin spine morphology s3: In lateral and medial views, the bodies of the spines are broad (Fig. 3(v)). The ventral margin of the preserved portions of the bones is nearly devoid of serration. Only the preserved upper part (most probably corresponding to the middle portion of the spine) possesses very small serrae.

The described forms of the unbranched last spine of the dorsal fin can clearly be distinguished from each other, including that of the Barbini indet, from the locality Karg1 2 by: (1) the shape, orientation and surface structure of the serrae; (2) the position where the serration appears on the spine; (3) the dimensions of the spine body.

In neoichthyological studies, the unbranched last spine of the dorsal fin and its serration are broadly used for taxonomic distinction between different genera or among species of the same genus (Kottelat and Freyhof 2007). Doadrio (1990) made an attempt to use the morphology and peculiarities of this spine for intergeneric taxonomy, but, unfortunately, did not include all barbin genera.

Taking into account the presence of three different morphologies of the unbranched last spine of the dorsal fin and eight tooth morphologies in the locality Hancili, we can assume the presence of at least three different barbin taxa, which could belong to the genera Barbus and/or Luciobarbus. More comprehensive studies on recent barbin genera are necessary to be able to identify certain tooth morphologies or dorsal spine morphologies to certain species.

Genus Capoeta Valenciennes, 1842 in Cuvier and Valenciennes, 1842 (sensu Yang et al., 2015)

\section{aff. Capoeta sp.}

Fig. 3(w, x)

Material: Loc. Hancili: tooth morphology d8 - one tooth (UU HAN 5317).

Description and remarks: a single tooth is simewhat anterodorsally compressed and spoon-shaped. The grinding surface is reduced and it is represented in the form of a narrow strip. The anterior margin of the tooth (anterior wall of the grinding surface) is lower than the posterior one. This morphology is reminiscent of the morphology of the pharyngeal teeth of the genus Capoeta (Ayvazyan et al. 2018), corresponding to character stage $\alpha 2$ of the lateral outline and $\beta 5$ of the transverse cross section. However, so far, a comparable morphology has not been reported for Capoeta (Ayvazyan et al. 2018). This tooth can be characterised by the character stage $\beta 5$ of the transverse cross section, but no corresponding character stage $\alpha$ of the lateral outline is found within the character stages given by Ayvazyan et al. (2018). Taking into account these observations, as well as that only one tooth has been found thus far, we prefer to assign the tooth tentatively to the genus Capoeta.

Barbini indet.

Fig. 3(y, ee)

Material: Loc. Karg1 1: 15 pharyngeal teeth isolated or attached to pharyngeal bone (UU KAR1 1300-1305). Loc. Karg1 2: 19 pharyngeal teeth isolated or attached to pharyngeal bone (UU KAR2 1301-1302, 1304-1306), one unbranched dorsal fin ray (UU KAR2 1303). Loc. Keseköy: 116 pharyngeal teeth isolated or attached to pharyngeal bone (UU KE 5305-5310).

Description: the pharyngeal teeth are mediolaterally compressed, small-sized and slender. The grinding surface is located at the anterior side of the tooth crown (Fig. 3(z, dd, aa, bb)). It is narrow and dorsoventrally elongated. In short teeth, the grinding 
Fig. 4 Salamander and some frogs from Turkish localities. a-I Salamandra sp., a-e trunk vertebra (UU BAG 1001) in anterior a, posterior b, right lateral c, dorsal $\mathbf{d}$ and ventral e views; $\mathbf{f}-\mathbf{i}$ caudal vertebra (UU HAR1 5055) from loc. Harami 1 in anterior $\mathbf{f}$, left lateral $\mathbf{g}$, dorsal $\mathbf{h}$ and ventral i views; $\mathbf{j}-\mathbf{l}$ humeri (UU BAG $1004 \mathbf{j}$ and $1003 \mathbf{~ k , ~} \mathbf{l}$ ) from loc. Bağiçi in ventral $\mathbf{j}, \mathbf{k}$ and dorsal $\mathbf{l}$ views. $\mathbf{m}-\mathbf{v}$ Pelobatidae indet. from $\mathbf{m}, \mathbf{n}$ loc. Harami 1, left maxilla (UU HAR1 5051) in labial $\mathbf{m}$ and lingul $\mathbf{n}$ views; o, p loc. Bağiçi, right maxilla (UU BAG 1001) in labial o and lingual p views; q, r loc. Keseköy, complete posterior half of right maxilla (UU KE 5006) in outer $\mathbf{q}$ and inner $\mathbf{r}$ views; $\mathbf{s}-\mathbf{v}$ loc. Hancili; right frontoparietal (UU HAN 5051) in ventral s)and dorsal $\mathbf{t}$ views; left frontoparietal (UU HAN 5052) in dorsal $\mathbf{u}$ and ventral $\mathbf{v}$ views. $\mathbf{w}-\mathbf{y}$ Bufonidae indet. from loc. Keseköy, right ilium (UU KE 5001) in lateral $\mathbf{w}$, ventrolateral $\mathbf{x}$ and medial $\mathbf{y}$ views. $\mathbf{z}$, aa Anura indet., fragment of left maxilla (UU KAR1 1051) in inner view $\mathbf{z}$, with magnified teeth of the same specimen in ventral view aa; bb phalanx, morphology A (UU HAR1 5056) in dorsal bb-1) and ventral bb-2 views; cc phalanx, morphology B (UU HAR1 5057) in dorsal bb-1 and ventral bb-2 views

surface is shifted dorsally, whereas in long teeth it corresponds to half of the entire tooth length. The grinding surface is surrounded by a moderately high crest, which displays uneven structures (serration-shaped) at its lateral wall. A well-developed hook is projected over the grinding surface. The hook is variably oriented-dorsoanteriorly (Fig. 3(y)) to anteriorly (Fig. 3(z)). At the posterior tooth positions (a1 or a2; Fig. 3(y, aa)), the teeth are more robust; the grinding surface is reduced. The preserved fragment of the last unbranched spine of the dorsal fin possesses three rather robust, short, pointy, ventroposteriorly directed serrae. Their surface is smooth (Fig. 3(ee)).

Remarks: The morphology of the pharyngeal teeth described here is, to the best of our knowledge, unknown both in the fossil record and among recent species. The shape of the teeth and the grinding surface has similarities with, e.g. Barbini indet. (?Barbus sp.) from Gračanica, Bosnia and Herzegovina, middle Miocene (Vasilyan in press). Apart from the tooth material, the presence of a fragment of the serrated last unbranched spine of the dorsal fin also suggests the presence of barbin (Kottelat and Freyhof 2007) fishes in the locality Karg1 1. Due to lack of comprehensively studied and comparative material of the pharyngeal dentition of the recent barbins, we prefer to assign these remains to the tribe Barbini.

Subfamily Leuciscinae Bonaparte, 1835

Genus Leuciscus Cuvier, 1816-1817

\section{Leuciscus sp.}

Fig. 3(ff)

Material: Loc. Hancili: three isolated pharyngeal teeth (UU HAN 5318-5320).

Description and remarks: The teeth are lateromedially compressed (Fig. 3(ff-1, ff-3)). The grinding surface is elongate, narrow and located at the anterior side of the tooth. Its surface is nearly smooth with some rugosities. Its lateral margin possesses up to five denticles with rounded tips. Ventrally, they become smaller. The dorsal tip of the tooth terminates with an anteriorly oriented hook. This morphology resembles that of the genus Leuciscus (Rutte 1962).

Cyprinidae indet.

Material: Loc. Keseköy: 17 fragments of pharyngeal bones (UU KE 5302-5304).

Remarks: fragments of the pharyngeal bone, indicating the placement (of different sizes) of the attachment of the pharyngeal teeth, are present. One or two rows are observable on the pharyngeal bones, where the teeth were positioned. Pharyngeal bones with dentition are widely known in cypriniform fishes, especially in the family Cyprinidae (Winfield and Nelson 1991). Considering that in this locality only cyprinid remains are known, we tentatively assign these pharyngeal elements to the family Cyprinidae.

Teleostei indet.

Material: Loc. Karg1 1: 14 vertebrae (UU KAR1 1303). Loc. Karg1 2: ten vertebrae (UU KAR2 1300). Loc. Keseköy: 17 atlases (UU KE 5301) and 128 trunk/caudal vertebrae (UU KE 5300). Loc. Hancili: one vertebra (UU HAN 5331).

Description and remarks: numerous vertebrae, including those from trunk and caudal positions, as well as the atlases, have been found. They show an amphicoelous morphology; the atlases are anteroposteriorly strongly flattened. Any further identification of the material is impossible.

Class Amphibia Linnaeus, 1758

Order Caudata Scopoli, 1777

Family Salamandridae Goldfuss, 1820

Genus Salamandra de Garsault et al., 1764

Salamandra sp.

Fig. 4(a-1)

Material: Loc. Harami 1: one caudal vertebra (UU HAR1 5055). Loc. Bağiçi: one trunk vertebra (UU BAG 1002) and two humeri (UU BAG 1003, UU BAG 1004).

Description: A relatively well-preserved trunk vertebra (UU BAG 1002) is present from the locality Bağiçi (Fig. 4(a-e)). It is remarkable in its large size. The centrum length measures 6 $\mathrm{mm}$. In lateral view, the neural arch and centrum are dorsoventrally flattened; due to this, both of them are low and broad. The opisthocoelous centrum is flexuous (arched dorsally). The prezygapophysis is connected with the parapophysis by a posteroventrally directed accessory alar process, whereas the postzygapophysis is connected with the diapophysis by a horizontally directed dorsal lamina. In anterior and posterior views, the neural canal is round and narrow. Several foramina of different sizes are piercing the bases of 
both prezygapophyses. The neural spine is missing, but the neural arch possesses traces of its base, suggesting that it reached nearly the anterior tip of the neural arch.

The anterior portion of a caudal vertebra (UU HAR1 5055) is preserved (Fig. 4(f-i)). In ventral view, the lateral edges of the vertebral centrum possess the base of the haemapophysis. The centrum possesses an anterior condyle, suggesting a probable opisthocoelous morphology of the vertebra. In anterior view, the neural arch is rounded; only its base is flat. Distinct subprezygapophyseal foramina can be observed at the base of the prezygapophysis. In lateral view, the neural spine is visible, arising behind the short zygosphene.

Distal portions of two humeri are present in the locality Bağiçi. The bones are lateromedially flattened. The lateral surface of the distal tip of the humeri possesses a longitudinal and rather shallow olecranon fossa. The shallow cubital ventral fossa of the humeri is observable on the medial surface of the bones. It has a semilunar outline. The capitum (radial condyle) is located at its base (UU BAG 1004, fig. 4j) or is missing (UU BAG 1003, fig. 4k-1). The humeri possess a small remnant of the humeral dorsal crista at their middiaphyseal position. The longest preserved humerus fragment (representing the distal half of the bone) measures $6 \mathrm{~mm}$, suggesting the humerus had the length of around 11-12 mm. Remarks: The large size of the bones and the observed morphology, i.e. dorsoventrally flattened, broad and robust trunk vertebrae; caudal vertebra with round neural canal and neural spine; and the general morphology of the humeral fragments, agrees with the genus Salamandra (Estes and Hoffstetter 1976; Rage 1984). Moreover, the large bone sizes agree with those of Salamandra sansaniensis (Estes and Hoffstetter 1976; Rage and Hossini 2000). Nevertheless, the lack of the studies on vertebral morphology of all recent Salamandra species, including that of the largest representative of the genus, i.e. Salamandra infraimmaculata, makes the reliable identification to the species level of the fossil remains impossible.

Order Anura Fischer, 1813

Family Pelobatidae Bonaparte, 1850

Pelobatidae indet.

Fig. 4(m-v)

Material: Loc. Harami 1: one fragmentary maxilla (UU HAR1 5051). Loc. Keseköy: one fragmentary maxilla (UU KE 5006). Loc. Hancilı: three frontoparietals (UU HAN 5051-5053). Loc. Bağiçi: one fragmentary maxilla (UU BAG 1001).

Description: All maxillae are fragmentary. The labial surface bears a pit-and-ridge ornamentation. The specimen UU HAR1 5051 (Harami 1; Fig. 4(m, n)) represents the smallest individual. Its surface is rather weathered, and, therefore, surface structures are poorly pronounced. In UU KE 5006 (Keseköy, fig. 4(q, r)), the bone exhibits a dorsal, posterodorsally inclined and relatively pointed zygomaticomaxillar process, and a posterior process. Its end appears to be undamaged (judging by the intact zygomaticomaxillar process), suggesting a broad contact with a short but robust quadratojugal. Between both processes, the margin of the bone is concave. In lingual view, UU KE 5006 (loc. Keseköy) and UU BAG 1001 (loc. Bağiçi) possess a moderately developed pit behind the pterygoid process (Fig. 4(p,r)). The pterygoid process is the prominent posterior termination of the horizontal lamina roofing the tooth row dorsally. The lamina horizontalis is represented by a rather sharp and relatively low flange in UU HAR1 5051 (loc. Harami 1), or by a distinct, robust flange with a rounded surface in UU KE 5006 (loc. Keseköy) and UU BAG 1001 (loc. Bağiçi). The latter maxilla, however, differs from that from Keseköy in the absence of the pterygoid process and a subdivided zygomaticomaxillar process. Unless these two features are artefacts caused by fossilisation, they could represent significant taxonomic differences.

Two frontoparietals from Hancilı roughly correspond to one another in their general shape and size (Fig. 4(s-v)). They are paired, which means that they were in contact with their counterparts from the opposite side in a slightly serrated median suture. Their orbital margin is nearly straight or only slightly concave, and it is deflected ventrally. Consequently, the tectum supraorbitale is poorly developed and does not extend into the orbit. The margo orbitalis ends posteriorly in a lateral process, which is discernible only because the margin of the frontoparietal breaks here and runs posteromedially. There, it terminates in a process which represents the most posterior part of the frontoparietal. The margin then turns sharply and runs anteromedially towards the posterior end of the median suture. This suggests that the posteromedial margins of both frontoparietals enclosed a nearly rectangular, wedge-like space originally filled with unpaired median element typical for pelobatids. The frontoparietal incrassation on the ventral surface of the bone is typically pelobatid-like, which means that it is undivided, broad posteriorly and narrower anteriorly. In a living animal, it fitted in a large fenestra in the roof of the endocranial braincase. The dorsal surface of the frontoparietal is covered by sculpture, which in UU HAN 5051 (Fig. 4(s, t)) is represented by indistinct ridges, arranged radially from the centre of the bone, while, in UU HAN 5052 (Fig. 4(u, v)), it is pustular in the middle, with indistinct radial ridges in the peripheral parts of the bone. Remarks: The general morphology of the maxilla, together with the morphology of the frontoparietals that corresponds to a postmetamorphic but not yet ultimate developmental stage of the Pelobatidae. The pit-and-ridge type of ornamentation is a combination of characters that indicate relations to the Pelobatidae (Roček 1981), but does not allow identification at the generic level (see "Discussion"). 
Family Bufonidae Gray, 1825

Bufonidae indet. (? Pseudepidalea sp.)

Fig. 4(w-y)

Material: Loc. Keseköy: one ilium (UU KE 5001).

Description: The fragment of this ilium measures $4.2 \mathrm{~mm}$ at its highest portion, corresponding to the highest point of the dorsal tubercle and lowest preserved point of the pars descendens. The anterior portion of the acetabulum and posterior part of the iliac shaft are preserved. The dorsal tubercle is pointy and well-pronounced; it is relatively high and broad. It is composed of two or three lobes (Fig. 4(w)). The anterior border of the acetabular rim is high. The pars descendens is moderately high. It narrows ventrally. A small preacetabular fossa pierces the anterodorsal corner between acetabulum and pars descendens. The iliac shaft has a rounded outline and flat surface. It does not possess any structures (Fig. 4(w)).

Remarks: The preserved ilium can be assigned to the family Bufonidae based on the combination of the following characters: pointy, bi-(tri-)lobed dorsal tubercle, flat medial surface; the iliac shaft is smooth and does not possess a dorsal crest (Blain et al. 2010). The family Bufonidae represents a group with numerous species distributed in both the Old and New Worlds (Frost 2014). The morphology of the ilium is broadly uniform in many forms (Tihen 1962; Sanchíz 1998), and other skeletal elements are necessary for closer identification. The comparison with both recent and fossil Western Asian bufonids reveals strong similarities in morphology (e.g. shape of the dorsal tubercle, moderately high pars descendance) and size to the genus Pseudepidalea (Blain et al. 2010) and can clearly be separated from the genus Bufo. Due to the incomplete preservation of the ilium and the lack of further skeletal elements as well as poor knowledge of the osteology of the family, we prefer to name the fossil bone from the locality Keseköy as Bufonidae indet. (? Pseudepidalea).

Family Alytidae Fitzinger, 1843

Genus Latonia von Meyer, 1843

\section{Latonia sp.}

Material: Loc. Karg1 1: four cranial bones (UU KAR1 10011005), seven maxillae (UU KAR1 1006-1011), one atlas (UU KAR1 1012), one vertebra (UU KAR1 1013), one costa (UU KAR1 1014), two sacral vertebrae (UU KAR1 1015-1016), one ilium (UU KAR1 1054), two urostyles (UU KAR1 10171018), one coracoid (UU KAR1 1019), one humerus (UU KAR1 1020), two radioulnae (UU KAR1 1021-1022). Loc. Karg1 2: eight maxillae (UU KAR2 1006-1012), three angulars (UU KAR2 1013-1015), one atlas (UU KAR2 1013), one vertebra (UU KAR2 1014), two transverse processes (UU KAR2 1015, 1016), two costae (UU KAR2 1017, 1018), 11 ilia (UU KAR2 1022-1032), three urostyles (UU KAR2 1019-1021), two coracoids (UU KAR2 1033, 1034), six humeri (UU KAR2 1035 -1040). Loc. Karg1 3: three maxillae (UU KAR3 1001-1003), one ilium (UU KAR3 1207). Loc. Harami 1: nine maxillae (UU HAR1 5062, 5062-1, 5062-2, 5062-3). Loc. Harami 3: one maxilla (UU HAR3 5052), one angular (UU KAR3 5012), two scapulae (UU HAR3 5051), one sacral vertebra (UU HAR3 5013), one costa (UU HAR3 5014), one ilium (UU HAR3 5015), one ischium (UU HAR3 5016). Loc. Keseköy: three angulars (UU KE 5012-5014), 71 maxillae (UU KE 5012-5019, 5184-5186), two atlases (UU KE 5020-5021), six scapulae (UU KE 5022-5025, 5180), four costae (UU KE 5026-5029), 46 humeri (UU KE 5096$5100,5104-5141,5177-5179)$, six transverse processes (UU KE 5030-5035), 55 urostyles (UU KE 5142-5176, 51815182). Loc. Hancilı: two frontoparietals (UU HAN 5054, 5055), four maxillary fragments (UU HAN 5056), one parasphenoid (UU HAN 5058), three vertebrae (UU HAN 5057). Loc. Çandır: six maxillae (UU CD 5001), three cranial bones (UU CD 5004), one atlas (UU CD 5002), three vertebral centra (UU CD 5003).

Description and remarks: The frontoparietal (UU HAN 5055) (Fig. 5(a, b)) preserves only its anterolateral portion, which is, fortunately, of utility for determination of the genus (Roček 1994). Its dorsal surface is horizontal, extending into the orbit by a thin supraorbital tectum. The dorsal surface in that part is covered by anteroposteriorly oriented rounded ridges, typical for Latonia gigantea (Roček 1994; fig. 7F). The frontoparietal incrassation in the middle portion of the inner surface of the bone is depressed, but rimmed with a prominent crista, which was part of the contacting surface with the braincase in the living animal. The scapula (UU HAR3 5051) (Fig. 5(c, d)) has an incomplete anterior margin, so its shape cannot be restored with certainty. It seems that it was rather short and squarish. The maxillae are preserved as short fragments (Fig. 5(g-1)), but the morphology of their inner surface, with the sulcus for the nasolacrimal duct, which is manifested also on the dorsal margin of the bone, is a typical feature of Latonia. The labial surface of the maxilla is flat. On the lateral surface of the ilium, at the level of the anterior margin of the acetabulum, a typical triangular depression is present which, in its most posterior part, is pierced by several foramina (filled with whitish sediment in Fig. 5(m)). This is also a typical feature of the genus Latonia. Finally, the opisthocoelous atlas, although with neural arches broken off, is also indicative of Latonia. However, it differs from the atlas of Latonia from the middle Miocene of Sansan and La Grive, St. Alban, in that both cotyles are interconnected (Fig. 5(f)). The morphology of the cranio-vertebral articulation is often considered important in anuran taxonomy, but nothing is known about individual and developmental variation of this anatomical character. 


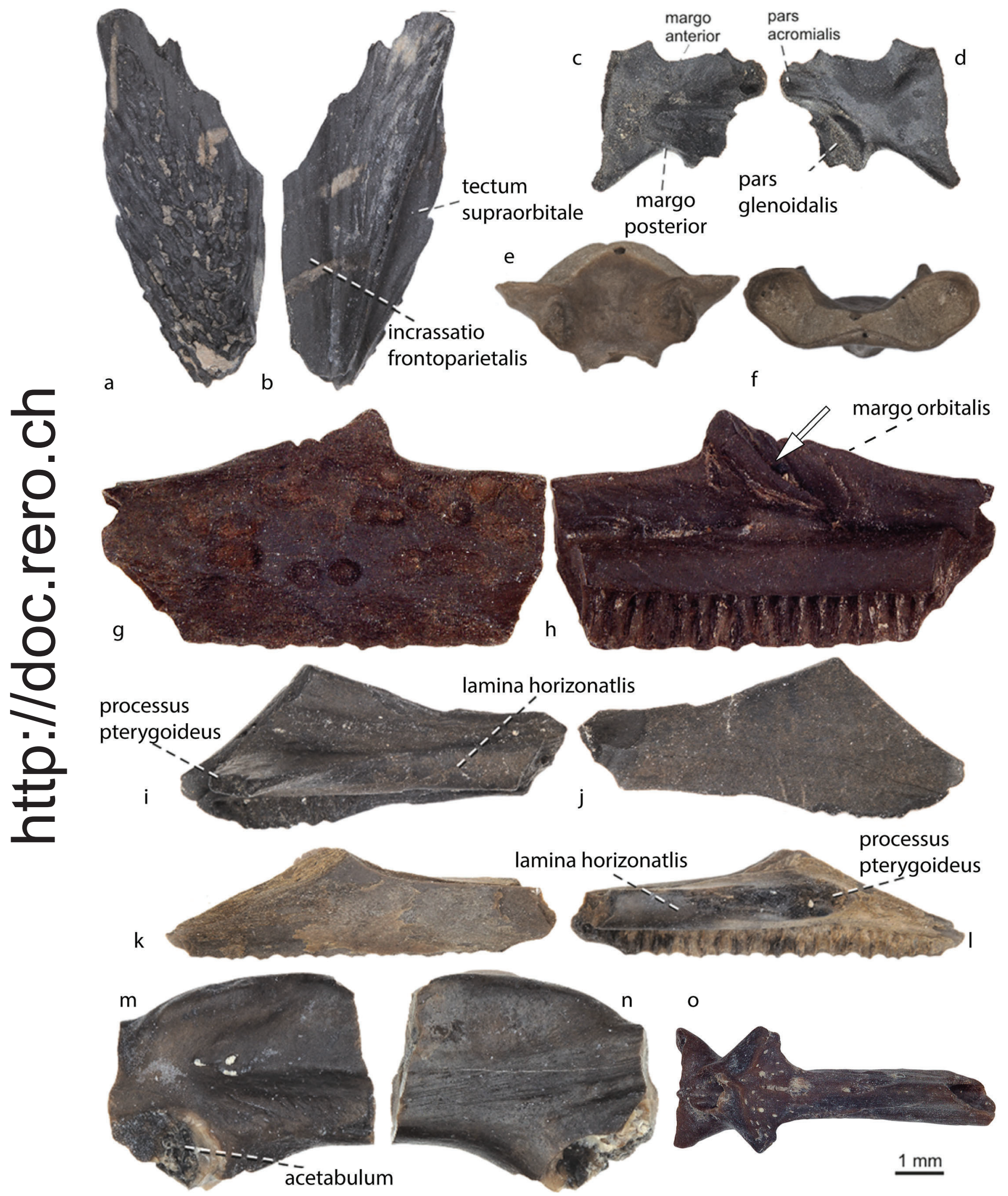


4ig. 5 Remains of Latonia from the studied Turkish localities. a, b Left part of the frontoparietal (UU HAN 5055) in dorsal a and ventral b views. c, d Right scapula (UU HAR3 5051) in inner $\mathbf{c}$ and outer $\mathbf{d}$ views. e, f Atlas (UU CD 5002) in dorsal e and anterior $\mathbf{f}$ views. $\mathbf{g}, \mathbf{h}$ Fragment of right maxilla (UU HAR1 5012-1) in labial $\mathbf{g}$ and lingual $\mathbf{h}$ ) views. The sulcus for the nasolacrimal duct, which runs posteroventrally on the inner surface of the bone, is marked by an arrow. $\mathbf{i}, \mathbf{j}$ Left maxilla (UU HAR1 5012-2) in lingual $\mathbf{i}$ and labial $\mathbf{j}$ views. $\mathbf{e}-\mathbf{k}$ Right maxilla (UU HAR1 5012-3) in labial $\mathbf{k}$ and lingual e views. m, n) Right ilium (UU KAR3 1207 ) in lateral $\mathbf{m}$ and medial $\mathbf{n}$ aspects. $\mathbf{o}$ urostyle (UU KE 5182) in dorsal view

The studied material is too fragmentary for more precise taxonomic evaluations, but the mentioned fragments of the frontoparietal (UU HAN 5055), maxilla (UU HAR1 5062-1) and ilium represent doubtless evidence of Latonia in the sample (Roček 1994).

\section{Family Palaeobatrachidae Cope, 1865}

\section{Palaeobatrachidae indet.}

Material: Loc. Karg1 1: one angular (UU KAR1 1052), two neural arches (UU KAR1 1053). Loc. Karg1 2: one angular (UU KAR2 1104), two scapulae (UU KAR2 1105), one humerus (UU KAR2 1001). Loc. Harami 1: one maxilla (UU HAR1 5059), six sphenethmoids (UU HAR1 5005-5007, 5060), eight angulars (UU HAR1 5001-5004, 5061), one scapula (UU HAR1 5009), one coracoid (UU HAR1 5010), 25 humeri (UU HAR1 5011-5035), one illium (UU HAR1 5008), two neural arches (UU HAR1 5054). Loc. Harami 3: one sphenethmoid (UU HAR3 5003), eight humeri (UU HAR3 5004-5011), two angulars (UU HAR3 5001-5001). Loc. Keseköy: five maxillae (UU KE 5183), one urostyle (UU KE 5011).

Description: The largest of the three sphenethmoids from Harami 1 is UU HAR1 5005 (Fig. 6(a-c)); its widest diameter is $5.65 \mathrm{~mm}$, so it represents a medium-sized individual, probably not exceeding SVL of $60 \mathrm{~mm}$. Its lateral processes display spongy bone but are symmetrical and not too prominent beyond the lamina supraorbitalis; this suggests that they were completed by cartilage in the living animal and that the exposed spongy bone is not an artefact. Similarly, the anterior median process (i.e. ossified part of the septum nasi) is not prominent beyond the floor of the nasal capsules (i.e. ossified part of the solum nasi). The anterior margin of the floor of the nasal capsules is almost straight and thick, and was undoubtedly extended by cartilage, whereas the anterior margin of the roof of the nasal capsules (i.e. ossified part of the tectum nasi) is deeply concave (Fig. 6(a)) and thin, and was not completed by cartilage (Fig. 6(c). The articular facet for the frontoparietal is slightly depressed due to the elevated margins, covered by a few irregular and indistinct grooves. The borderline between the contact facets for the nasals and the frontoparietal indicates the shape of the anterior margin of the frontoparietal, which extended in a median point. On the right side, the posterior margin of the lateral braincase wall is covered by periost, which suggests its natural anteroposterior extent. This, compared with the maximum width of the bone, suggests that the sphenethmoid was not elongated, but approximately as long as broad. The bottom of the braincase reached posteriorly at least the same level as the lateral walls or more. The roof is only moderately incised anteriorly (incisura semielliptica sensu Hossini and Rage 2000). The ventral surface of the bottom of the braincase is rimmed by a rounded ridge on either side; the ridges are at the transition between the bottom and lateral walls of the braincase and delimit laterally the groovelike articular facet for the parasphenoid. The braincase is connected with each nasal capsule by a canal for the olfactory nerve (canalis olfactorius). The medial section of the ossified part of the postnasal wall is pierced by a canal for the medial branch of the ophthalmic nerve (ramus medialis nervi ophthalmici), which enters the nasal capsule dorsolaterally to the orifice of the canalis olfactorius (Fig. 6(c)). Although the orbitonasal canal is ellipsoid in cross section, the longest diameters of both canals are about of the same size.

In contrast to UU HAR1 5005 (Fig. 6(a-c)), UU HAR1 5006 (Fig. 6(d-f)) is small, with its widest diameter about 3.6 $\mathrm{mm}$; this should correspond to an individual with SVL of approximately $40 \mathrm{~mm}$. Although this sphenethmoid is rather worn out anteriorly and posteriorly (hence shorter than broad), the nasal facets and the groove for the parasphenoid are similar to UU HAR1 5005. Principal differences between both bones are the narrow contact facet for the frontoparietal (Fig. 6(d)) and deeply $\mathrm{V}$-incised incisura semielliptica, which reaches up to the level of the partition between both olfactory canals. Also, the canals entering the nasal capsules are rather different (canalis olfactorius is much larger than that for the medial branch of the ophthalmicus nerve). On the left side of the bone, both fuse with one another close to their entrance into the nasal capsule, but this may present individual variation. Notably, both the floor and the roof of the nasal capsules were completed by cartilage in life, which suggests that the differences between both sphenethmoids are due to differences in their degree of development, rather than an indication of two different species. Alternatively, they might be a result of developmental heterochrony of two closely related species, as is the case with recent Bombina bombina and B. variegata.

The angulars UU HAR1 5004 (Fig. 6(g)), UU HAR1 5002 (Fig. 6(h)) and UU HAR1 5001 (Fig. 6(i, j)) all have a dorsoventrally compressed coronoid process, which continues posteriorly by a long, horizontal ridge extending to the dorsomedial margin of the bone, where it meets with the gradually lowering medial wall of the Meckelian groove (marked by an arrow in Fig. 6(g)); whereas anteriorly, the coronoid process terminates rather abruptly. Moreover, all these angulars have a tubercle or protuberance on the dorsal edge of the medial wall of the Meckelan groove and a smooth, depressed area for the adductor mandibulae externus muscle. There is 


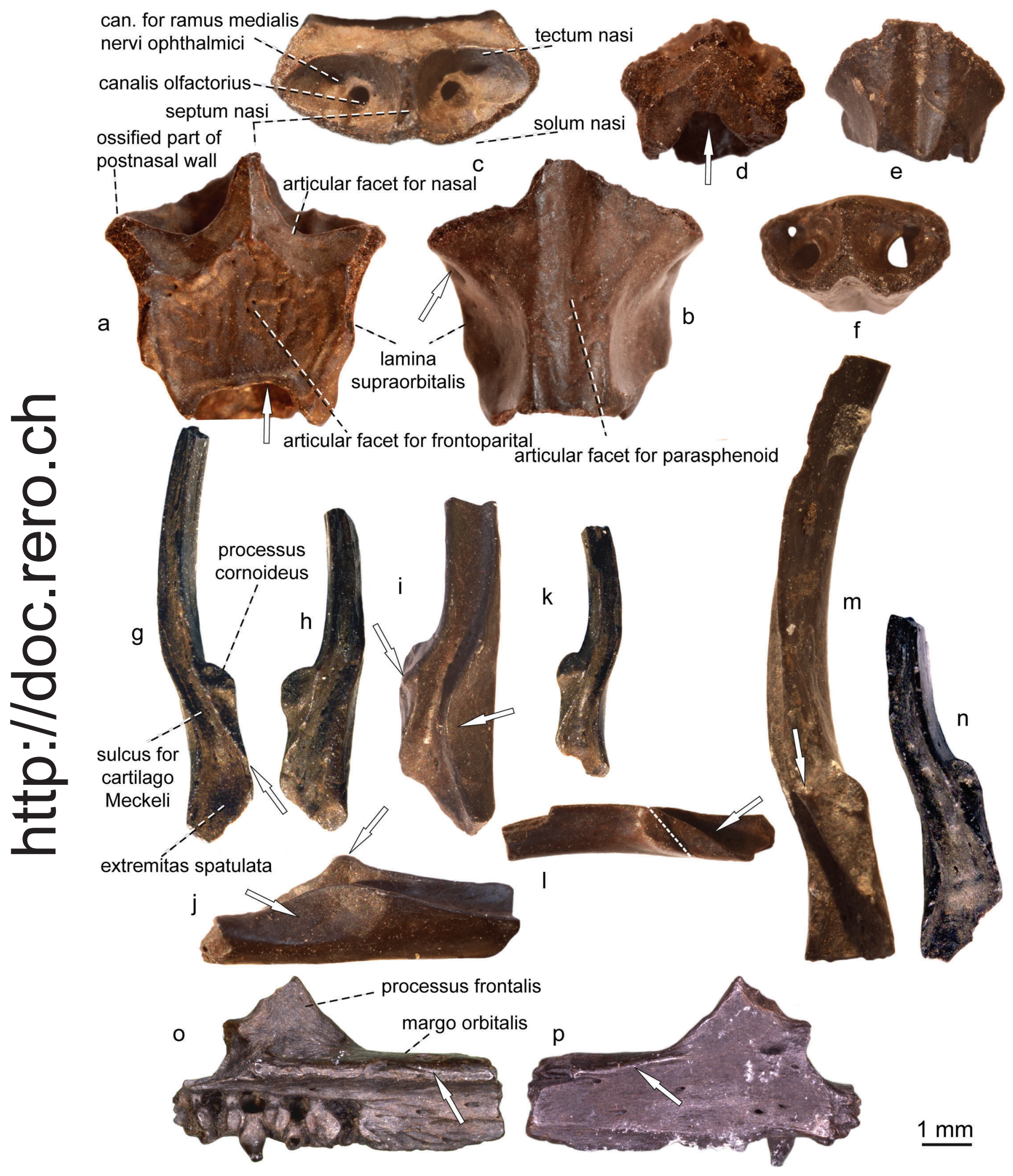


Fig. 6 Cranial elements of Palaeobatrachidae. a-c Sphenethmoid UU HAR1 5005 from loc. Harami 1 in dorsal a, ventral b, and anterior c views. The arrow in a marks the braincase cavity; the arrow in $\mathbf{b}$ marks the posterior orifice of the canal for the ramus medialis nervi ophthalmici. d-f Sphenethmoid UU HAR1 5006 from loc. Harami 1 in dorsal d, ventral e and anterior $\mathbf{f}$ views. g Left angular UU HAR1 5004 in dorsal view. Note a distinct ridge on the dorsal surface of the coronoid process, separating anterior and posterior depression. The posterior margin of the coronoid process is nearly straight, reaching the medial margin of the bone at the level of the posterior end of the medial wall of the sulcus Meckeli (marked by arrow). h Right angular UU HAR1 5002 in dorsal view. $\mathbf{i}-\mathbf{j}$ Right angular UU HAR1 5001 in dorsolateral $\mathbf{i}$ and lateral $\mathbf{j}$ views; the arrows mark tubercle protruding from the medial wall of the Meckelian groove, and a distinct concavity on the lateral surface. $\mathbf{k}$, Posterior part of right angular UU HAR1 5003 in dorsomedial $\mathbf{k}$ and medial I views; the longitudinal axis of the coronoid process is marked by a white broken line; the arrow marks the medial wall of the Meckelian groove. Note absence of a tubercle or protuberance on dorsal margin of the wall. m Left angular UU HAR3 5001 from loc. Harami 3 in dorsomedial view; the arrow marks a tubercle protruding from the medial wall of the Meckelian groove, as in i. n Left angular UU HAR3 5002 in dorsal view. o, p Right maxilla (UU HAR1 5059) in lingual $\mathbf{o}$ and labial $\mathbf{p}$ views. The white arrow in $\mathbf{o}$ points to a contact ridge with the pterygoid that in $\mathbf{p}$ marks a horizontal ledge that extends labially

some variation in the shape of the coronoid process - it may be divided by a delicate ridge or crista into the anterior and posterior flat or slightly depressed areas, or can be a single convexity. However, the right angular UU HAR1 5003 (Fig. $6(\mathrm{k}, \mathrm{l}))$ is different, especially in the position and shape of the coronoid process. In medial view (Fig. 6(1)), the coronoid process has a markedly oblique position, with its longitudinal axis slanting down posteriorly, so its posterior margin is located almost at the level of the ventral surface of the bone. In dorsal aspect, it is markedly prominent medially. In addition, the medial wall of the Meckelian groove is not extended dorsally. It exhibits similarity with MNHN LAU 11 from the early Miocene of Laugnac (Hossini and Rage 2000, fig. 1-2). Two angulars from Harami 3 are less well-preserved (Fig. 6(m,n)), but fit within the range of variation of the angulars knwons from Harami 1 (and of Palaeobatrachus in general).

A relatively complete maxilla is preserved from Harami 1 (UU HAR1 5059; Fig. 6(o, p)). The tooth row clearly terminates below the posterior base of the frontal process and the most posterior tooth position has the same size as the more anterior ones. The orbital margin is a flat, horizontal plate, extending labially in a distinct ledge (marked by an arrow in Fig. 6(p)). In addition, the frontal process is clearly inclined anteriorly.

One fragmentary scapula (UU HAR1 5009) from Harami 1 is available (Fig. $7(\mathrm{a}-\mathrm{c})$ ). Both its anterior and posterior margins are concave, and its distal (suprascapular) portion is narrower than the proximal part. As in other Palaeobatrachidae, the glenoidal and acromial parts and their articular cavities are separated by a deep depression (Fig. 7(c)), but not by a complete incisure into the outlines of the bone. The urostyle (UU KE 5011) from Keseköy is rather worn out, such that both condyloid fossae lost their lateral margins and the intercondyloid process seems to be remarkably prominent anteriorly (Fig. 7(f)), but this can also be an artefact of preservation. On the other hand, two longitudinal, parallel ridges close to the midline on the dorsal surface of the bone, typical for Palaeobatrachus, are clearly visible both in dorsal and anterior aspects. The ilium (UU HAR1 5008) from Harami 1 markedly differs from the ilia of other Palaeobatrachidae by its reduced pars ascendens (even if it were partly damaged in this region), extremely large acetabulum (well-visible in medial aspect; Fig. 7(e)), indistinct tuber superius, which is neither prominent dorsally nor laterally, and by a spike-like spina iliaca (marked by an arrow in Fig. 7(e)).

The humeri (Fig. 7(h-u)) are the most numerous among all skeletal elements, even if none of them is complete. They vary in their size, proportions of the medial and lateral epicondyles and by relative size and position of the caput humeri. In the great majority of the specimens, there is no cubital fossa, so the caput humeri is continuous with the ventral surface of the humeral shaft, but it seems that in large individuals, there is a narrow, semilunar depression parallel with the proximal surface of the caput humeri (Fig. 7(h)). This would suggest that relatively large individuals bent the fore limb in the elbow joint, such that the capitulum of the radioulna inserted into this depression, whereas in smaller (= younger) individuals, the fore limbs were stretched forwards, as is the case with swimming Xenopus. Besides this speculative interpretation, no taxonomic conclusions can be inferred from the morphological variation of the humeri.

Remarks: The sphenethmoid is the ossified portion of the anterior part of the braincase with adjacent parts of the septum nasi and postnasal walls, so the degree of its ossification may be used in assessing relative ontogenetic stages. In fully developed adults, ossified parts of the postnasal walls, septum nasi and braincase walls should be more extensive, compared with their cartilaginous portions, than in juveniles of the same species. In Palaeobatrachus, this may be combined with fusion of the sphenethmoid with some dermal bones, like the frontoparietal and parasphenoid. The maxilla is remarkable by the clearly reduced number of tooth positions, which is characteristic for Pliocene and Pleistocene species of Palaeobatrachus, such as $P$. eurydices and P. langhae, whereas Oligocene taxa have a higher number of small teeth. The scapula seems to be different from those of Oligocene species by its markedly concave anterior margin and narrow suprascapular portion. So, for instance, Palaeobatrachus from Enspel has the anterior margin straight, meeting with the suprascapular margin in a right angle.

\section{Anura indet.}

Fig. 4(z-ze)

Material: loc. Karg1 1: one maxilla fragment (UU KAR1 1051). Loc. Harami 1: three radioulnae (UU HAR1 5052), one neural arch (UU HAR1 5053), three phalanges (UU 


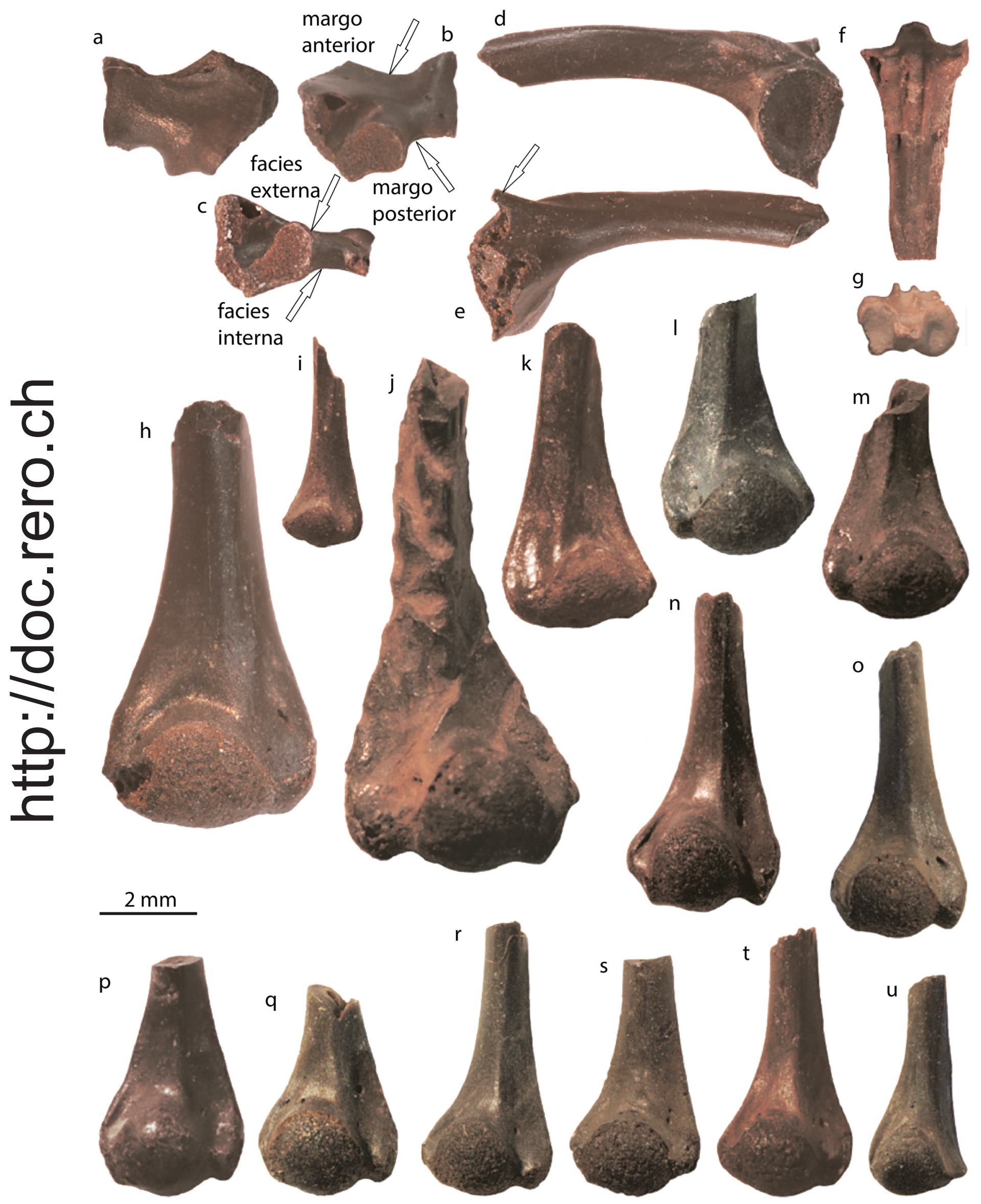


Fig. 7 Postcranial elements of Palaeobatrachidae. a-c Left scapula (UU HAR1 5009) from loc. Harami 1 in lateral $\mathbf{a}$, medial $\mathbf{b}$ and posteromedial c views. The arrows in $\mathbf{b}$ mark the anterior and posterior margins of the bone; the arrows in $\mathbf{c}$ mark the external and internal surfaces of the bone. d, e Left ilium (UU HAR1 5008) in lateral d and medial e views. Note prominent spina iliaca (marked by an arrow in e). f, $\mathbf{g}$ Urostyle (UU KE 5011) from loc. Keseköy in dorsal $\mathbf{f}$ and anterior $\mathbf{g}$ views. h Right humerus (UU KAR2 5000) from loc. Kargi 2. i-m Variation of humeri from loc. Harami 3. i Right humerus (UU HAR3 5006). j Left humerus (UU HAR3 5005). k Left humerus (UU HAR3 5007). I Left humerus (UU HAR3 5004). m Left humerus (UU HAR3 5008). $\mathbf{n}-\mathbf{u}$ ) Variation of right humeri from loc. Harami 1. n UU HAR1 5022, o UU HAR1 5023 (mirrored for comparison), p UU HAR1 5011, q UU HAR1 5026, r UU HAR1 5024, s UU HAR1 5021, t UU HAR1 5015, u UU HAR1-5031

HAR1 5056-5058). Loc. Bağiçi: one radioulna (UU BAG 1203).

Description: Two different morphologies of phalanges are present in Harami 1. Those of the morphology A (one phalanx, UU HAR1 5056, Fig. 4(bb)) are robust and triangular; the bulb is large and possesses well-developed rugosities on its surface. The phalanges of the morphology B (two phalanges, UU HAR1 5057, 5058, Fig. 4(cc)) are shorter but slender; the bulb is rounded with less rugosities than in the morphology $\mathrm{A}$.

The fragment of a maxilla (UU KAR1 1051) with both teeth and tooth pedicles is preserved from the locality Karg1 1 (Fig. 4(z-aa)). The teeth are bicuspid and inclined lingually at their tips. The labial cusps are smaller than the lingual ones. Their labial surface is smooth with few small nutrition foramina.

Remarks: The phalanges can be clearly assigned to the Anura based on their morphology (Kamermans and Vences 2009), but any precise identification is impossible. The tooth morphology of the maxilla from Karg1 1 resembles that of, e.g. Ranidae, Alytidae, Pelobatidae, Bombinatoridae and Hylidae (Greven and Laumeier 1987; Greven and Ritz 2008/2009). Other families, such as Palaeobatrachidae (with nonpedicellated and monocuspid teeth, and with knobs between teeth) (Wuttke et al. 2012) or Bufonidae (no teeth on maxilla) (Sanchíz 1998) can be excluded. Thus, this maxilla can be classified only as Anura indet.

Class Reptilia Laurenti, 1768

Order Squamata Oppel, 1811

Family Anguidae Gray, 1825

Genus Pseudopus Merrem, 1820

Pseudopus sp.

Fig. 8(a,b)

Material: Loc. Karg1 1: one jaw fragment (UU KAR1 1205). Loc. Karg1 2: one tooth (UU KAR2 1204).

Description and remarks: A jaw fragment with two teeth (UU KAR1 1205, Fig. 8(a)) and an isolated tooth (UU KAR2 1204, Fig. 8(b)) are preserved. The teeth are robust, cylindrical to conical, subpleurodont and stout. Lateromedially, they are slightly compressed. There are distinct striae observable on the crown. The lateral and medial surfaces of the crowns possess striae directed vertically (to the tooth axis). The anterior and posterior edges possess moderately (UU KAR1 1205) or weakly developed (UU KAR2 1204) cutting edges. The observed morphology on the available tooth material allows its identification as Pseudopus (Klembara et al. 2014). Also, the rather molariform morphology of teeth suggest they represent elements from the posterior part of the jaws (Klembara et al. 2014).

Genus Ophisaurus Daudin, 1803

Ophisaurus sp.

Material: Loc. Karg1 2: five trunk vertebrae (UU KAR2 1201). Description and remarks: These remains represent additional bone remains to the earlier published material of Ophisaurus sp. in Čerňanský et al. (2017). See description and discussion therein.

Anguinae indet.

Fig. 8(c-e)

Material: Loc. Karg1 2: one right dentary (UU KAR2 1203), two osteoderms (UU KAR2 1202). Loc. Karg1 3: two osteoderms (UU KAR3 1202). Loc. Çandır: 22 osteoderms (UU CD 5207, 5208), one vertebra (UU CD 5209). Loc. Bağiçi: three osteoderms (UU BAG 1200).

Description and remarks: An anterior portion of a dentary (UU KAR1 1203, Fig. 8(c)) is available from the locality Karg1 2 . The labial surface is smooth, possessing only three mental foramina. In lingual view, five tooth positions are visible. The base of the preserved tooth pedicles is pierced by small foramina. The subdental shelf (sensu Evans 2008; dental crest sensu Klembara et al. 2014) is low and has a rounded surface. The dental lamina is more than twice as high as the subdental shelf. The Meckelian groove is narrow and exposed ventrally. The symphysis projects linguoposteriorly. The preserved anterior portion of the dentary without teeth can be identified as Anguinae indet. based on the ventrally exposed Meckelian groove and general shape of the bone (Klembara et al. 2014).

Besides the herein described jaw material, we list in the material a further vertebra and osteoderms representing additional material to the already published remains of anguins from Turkish localities (Čerňanský et al. 2017).

Family Lacertidae Oppel, 1811

Lacertidae indet. 1

Fig. $8(\mathrm{f}-\mathrm{h})$

Material: Loc. Karg1 1: one dentary (UU KAR1 1206).

Description: The dentary is partially preserved with 14 tooth positions. The bone is robust; the subdental shelf is thick, massive and widens anteriorly (Fig. 8(h)). The Meckelian 


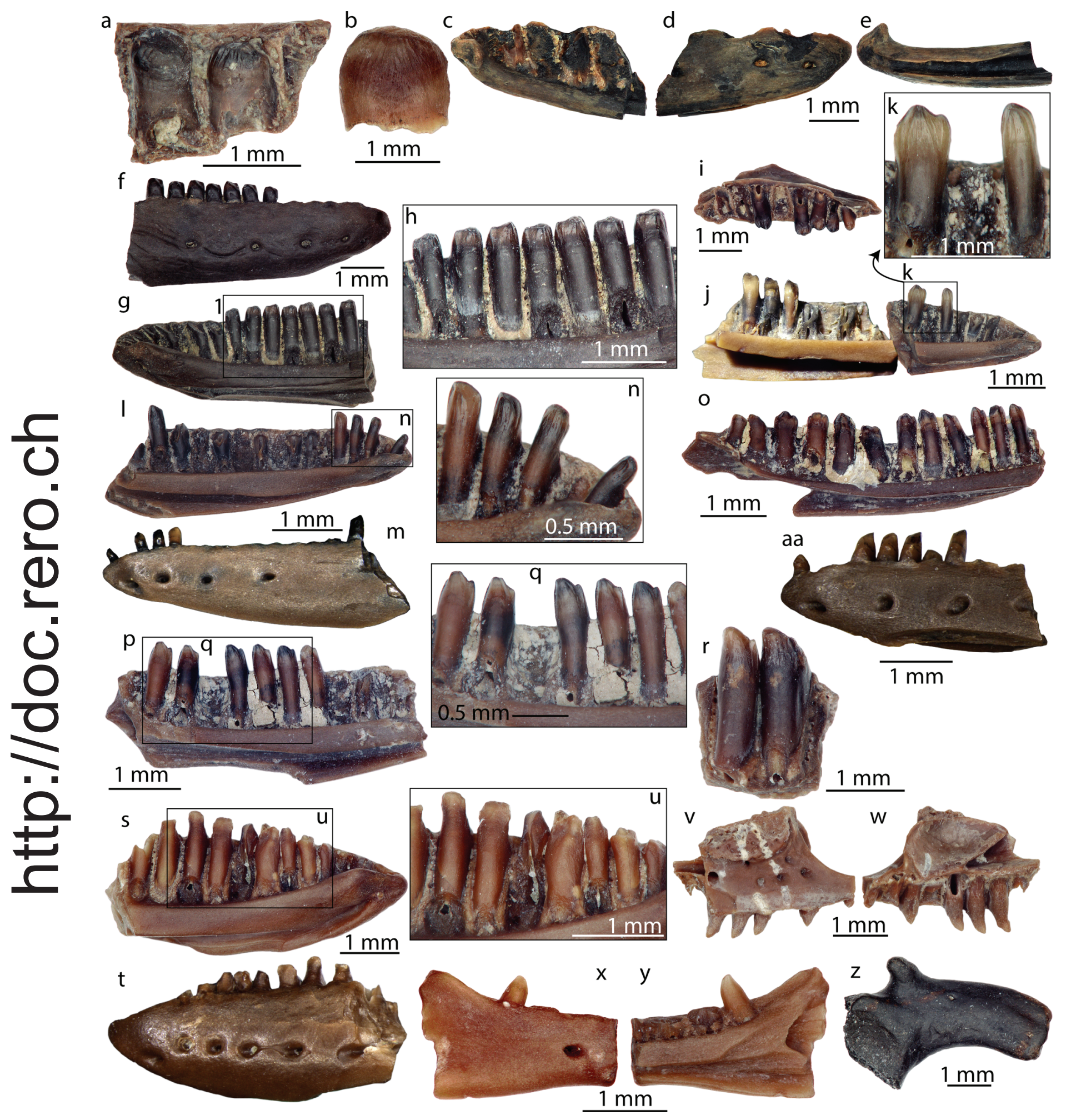

groove opens lingually. The teeth are pleurodont, bicuspid, short and robust. They are located close to each other. Their apices are oriented posterolingually. The tooth crown possesses a large main, blunt cusp and a small mesial (anterior) cusps. The main cusp shows at its lingual surface vertical striae terminating apically at the cusp tip. The dental lamina is relatively high, reaching the bases of the tooth crown (Fig. $8(\mathrm{f})$ ). The labial surface of the dentary is pierced by five smallsized mental foramina, which are arranged in a row and located in the lower half of the bone.

Remarks: see Remarks of Lacertidae indet. 4. 
Fig. 8 Lizard remains from the studied Turkish localities. a, b teeth of Pseudopus sp. from loc. Karg1 1 (a-UU KAR1 1205) and loc. Karg1 2 (b-UU KAR2 1204), c-e Anguidae indet. from loc. Karg1 2 (UU KAR2 1203 - right dentary). f-h Lacertidae indet. 1 from Karg1 1 (UU KAR1 1206-right dentary), in labial $\mathbf{f}$ and lingual $\mathbf{g}, \mathbf{h}$-magnified view on teeth. i-o Lacertidae indet. 2 from loc. Keseköy (i UU KE 5200maxilla, j, k UU KE 5206-left dentary, I-n UU KE 5213-left dentary, o UU KE 5219-left dentary, magnified views on teeth of the specimens $\mathbf{k}$ UU KE 5206, and $\mathbf{n}$ UU KE 5213. p, r, aa Lacertidae indet. 3 from loc. Keseköy p, q UU KE 5220-left dentary) (q-magnified view on the teeth of the specimen UU KE 5220) (aa UU KE 5215left dentary), from loc. Çandır (r-UU CD 5210 - right dentary). s-u Lacertiade indet. 4 from loc. Çandır UU CD 5202-left dentary, u magnified view on the teeth of the specimen UU CD 5202. v, w Lacertidae indet. from loc. Bağiçi (UU BAG 1201—right maxillae). x, y Blanidae indet. (? Blanus sp.) from loc. Çandır (UU CD 5204 right dentary). z - right ilium of Lacertilia indet. (UU KAR1 1208). All bones are figured from lingual view, except for $\mathbf{d}, \mathbf{f}, \mathbf{v}, \mathbf{x}$ figured in labial view and $\mathbf{e}$ in ventral view

Lacertidae indet. 2

Fig. 8(i-o)

Material: Loc. Keseköy: ten maxillae (UU KE 5200-5202), 15 dentaries (UU KE 5203-5206, 5213). Loc. Çandır: one dentary (UU CD 5200).

Description: The dentary is slender. The subdental shelf is flat posteriorly to rounded anteriorly (Fig. 8(j)). It has nearly the same height along its length, but at the 9-10th tooth positions, it increases in height. The ventral margin of the bone and the subdental shelf run close and subparallel to each other. The Meckelian groove is lingually exposed, but anteriorly, it changes its orientation rather ventrally (Fig. 8(j, 1)). The symphyseal part of the bone is reduced. The dentition is remarkably heterodont: four different tooth morphologies can be observed.

The first morphology resembles that of the skinks. Located at the first tooth positions (1-5th positions in UU KE 5213, Fig. 8(1, n); 1(?)-7th positions in UU KE 5206, Fig. 8(j, k)), the teeth are slender, monocuspid and pointed. At the lingual surface, the tooth crown possesses vertical striae, directed to the tooth tip. The crista lingualis and crista labialis are separated (no connection with carina intercuspidalis) and run parallel to each other. The former one is less pronounced than the latter. The antrum intercristatum is broad. The crista labialis is slightly projecting over the antrum intercristatum.

The second morphology is characterised by rather short, robust bicuspid teeth with rounded crowns. The lingual surface of the crown possesses vertical striae fusing at the tip of the tooth. The main cusp is larger and higher than the lateral one. In the tooth row, the second morphology can be observed posteriorly to the teeth of the first morphology (8th tooth position, UU KE 5206, Fig. 8(k)) and on the maxilla (UU KE 5200, Fig. 8(i)).

The third tooth morphology resembles the typical lacertid morphology, widely found in European Neogene and recent forms. The tooth is bicuspid, cylindrical, with a sharp apex. The tooth crown composes of a large main cusp and small lateral (anterior) cusp. The lingual surface of the tooth crown is nearly flat or bears weakly developed vertical striae. The third morphology can be observed in the middle or posterior half of the dentary (15th tooth positions in UU KE 5200, Fig. 8(j) and UU KE 5213, Fig. 8(1)).

The fourth morphology is represented by short and robust tricuspid teeth. The crown has a smooth surface. It is composed of the main (central) large cusp and two anterior and posterior cusps. The anterior cusp is slightly larger than the posterior one (last tooth positions, UU KE 5219, Fig. 8(o)).

The teeth are oriented anteriorly in the first three tooth positions. Furtherback in the tooth row, the teeth change their orientation to a posterior direction. In labial view, the dentary has a smooth surface and possesses at least five mental foramina, which are arranged in a row. The first foramen is located very close to the symphysis and opens anteriorly. Three first foramina are located close to each other (at the 1st, 4th and 7th tooth positions correspondingly), whereas the last two ones are at the 11th and 15-16th tooth positions (UU KE 5213, Fig. 8(1-n))

Remarks: see Remarks of Lacertidae indet. 4.

Lacertidae indet. 3

Fig. $8(\mathrm{p}-\mathrm{r}, \mathrm{aa})$

Material: Loc. Keseköy: eight maxillae (UU KE 52075210), 16 dentaries (UU KE 5211-5212, 5214-5216, 5220). Loc. Hancılı: one maxilla (UU HAN 5200). Loc. Çandır: four jaw bones (UU CD 5201, 5210).

Description: The dentaries are fragmentarily preserved. The subdental shelf is flat. The Meckelian groove exposes lingually. All teeth, including the posterior ones, are bicuspid, cylindrical, with sharp apices. The main cusp is large and pointed; it possesses at its lingual surface weakly developed vertical striae. The small lateral (anterior) cusp is significantly lower than the main one. All preserved teeth are oriented posteriorly. In labial view, the bone possesses four rather large mental foramina (UU KE 5215, Fig. 8(aa)), which are located in the preserved specimen along the first 12 tooth positions.

Remarks: see Remarks of Lacertidae indet. 4.

Lacertidae indet. 4

Fig. 8(s-u)

Material: Loc. Çandır: one dentary (UU CD 5202).

Description: The preserved dentary is robust. The dental shelf is high with a flat surface. The symphysis is reduced. The teeth are arranged close to each other. The dentition is heterodont. At the sixth tooth position, the tooth crown is bicuspid, with large main cusp and small anterior cusp (Fig. $8(\mathrm{u})$ ). At the seventh tooth position, the tooth is thick; the tooth crown is bicuspid with clearly separated pointy cusps, which are nearly similar in height. At the 9-10th tooth 
positions, the tooth crowns are monocupid, with a rounded, spoon-shaped cusp. All teeth have smooth lingual surfaces. The Meckelian groove is narrow and opens linguoventrally; anteriorly, it turns more ventrally. The labial surface of the bone is pierced by six, closely situated, rather large mental foramina. Among them, the first one is located slightly ventrally from the main row (Fig. $8(\mathrm{t})$ ).

Remarks: The described four forms of lacertid lizards can be clearly distinguished from each other by several characters:

1) The mental foramina:

a. In Lacertidae indet. 1 they are small in size, arranged at the ventral half of the bone and not very far from each other;

b. In Lacertidae indet. 2 the foramina are larger than in Lacertidae indet. 1, and the first three-four foramina are closely located to each other; a further foramen is located significantly further from the rest;

c. In Lacertidae indet. 3 the foramina are larger, and they are arranged rather closer to each than in Lacertidae indet. 2;

d. The mental foramina are small and located very close to each other in Lacertidae indet. 4.

2) Dentition:

a. Lacertidae indet. 2 and 4 have heterodont dentition with four and (at least) two morphologies, respectively.

b. Lacertidae indet. 1 has the shortest and thickest teeth in comparison to the other studied forms.

c. Lacertidae indet. 3 has a typical lacertid dentition, commonly found in all fossil and recent species of the genus.

3) The subdental shelf:

a. It is robust, massive and (mostly) well-pronounced in Lacertidae indet. 1,

b. Lacertidae indet. 4 has a slightly less robust subdental shelf than Lacertidae indet. 1, but it is still more pronounced than in Lacertidae indet. 2 and Lacertidae indet. 3;

c. Lacertidae indet. 2 and Lacertidae indet. 3 have a slender subdental shelf, which is significantly less developed than in Lacertidae indet. 1 and/or Lacertidae indet. 4.

Taxonomic considerations: Remarkable is the presence of two lizards, Lacertidae indet. 2 and 4, with heterodont dentition. Heterodont dentition has been earlier reported in fossil lizards, e.g. Miolacerta (Roček 1984), Lacerta filholi (Müller 1996) and Scincidae gen. et sp. indet. from Gratkorn (Böhme and Vasilyan 2014) (the last taxon should be considered to belong to the family Lacertidae, pers. observations of DV). In many forms, the heterodonty was characterised by the presence of anterior monocuspid teeth, posteriorly becoming bicuspid or tricuspid, or forms with bicuspid teeth changing posteriorly to fully a tricuspid tooth morphology. Until now, in different works, these forms have been described by comparing to a limited number of lacertid genera, without including, e.g. (Anatololacerta, Parvilacerta) and Southern Caucasian (Darevskia, Iranlacerta) genera. Kosma (2004) provides a rather comprehensive study on the dentition of this family, describing the dentition of some species from non-European genera. According to him, the heterodont dentition among lacertids, with up to three different tooth morphologies (mono-, biand tricuspid), can be observed in some species of the genera Darevskia, Algyroides, Lacerta and Iberolacerta. Among these lizards, Darevskia rudis (Kosma, 2004; fig. 28 ) is characterised by three tooth morphologies (1-3), which we can observe in Lacertidae indet. 2. Moreover, the tooth crown in D. rudis is divided into a prominent cuspis labialis and a lower cuspis lingualis and bears lingually a fine striation. These characters have been also found in the Lacertidae indet. 2, both from the localities of Keseköy and Çandır. Darevskia chlorogaster (Kosma 2004) does not show the tricuspid teeth (only mono- and bicuspid), but has a similar structure of the tooth crown (Kosma 2004). Nonetheless, to refer the Lacertidae indet. 2 to Darevskia, Algyroides or any other genera, a large comparative osteological study is necessary in order to document the osteological differences among the genera and species. Nevertheless, the affiliation of the Lacertidae indet. 2 to the Western Asian lacertids seems most plausible.

It is important to note that our observations pull into question the validity of the genus Miolacerta (Roček 1984), also considering the fact that the genus has been erected using only limited lacertid genera for comparison.

Further identification or comparison of Lacertidae indet. 1, 3 and 4 is difficult due to the presence of generic characters (bicuspid teeth) or the lack of available osteological collections and of comprehensive osteological studies on lizards.

Lacertidae indet.

Fig. 8(v, w)

Material: Loc. Keseköy: five dentaries (UU KE 5217). Loc. Çandır: one dentary (UU CD 5203). Loc. Bağiçi: one maxilla (UU BAG 1201).

Description and remarks: The available dentaries are poorly preserved. They possess few bicuspid teeth of different sizes, which are characteristic to the family Lacertidae (Kosma 2004). Due to the poor preservation, any further taxonomic identification is impossible.

The partially preserved maxilla possesses pleurodont, linguoposteriorly directed bicuspid teeth (Fig. 8(v, w)). Parallel to the ventral margin of the maxilla, a row of four rounded foramina for mandibular division of the fifth cranial nerve are present. Above the foramina, the bone possesses dermal ornamentation on the labial surface of the bone, composed of small pits (Fig. $8(\mathrm{v})$ ). The premaxillar process is mainly broken. In lingual view, a prominent arched ridge is 
present, which builds the anterodorsal wall for a rather deep cavity. Anteriorly to the arched ridge, the surface of the bone is concave and builds a rather deep depression. The combination of characters such as bicuspid pleurodont teeth and the presence of dermal ornamentation have been found in Lacerta cf. viridis (Venczel 2006). However, as recently has been reported (Villa 2018), the dermal ornamentation can be found in different lacertid genera. Thus, an open nomenclature at the family level is preferable for the maxilla from Çandır (Lacertidae indet.)

Amphisbaenia Gray, 1844

Family Blanidae Kearney, 2003

Blanidae indet. (? Blanus sp.)

Fig. 8(x,y)

Material: Loc. Çandır: one dentary (UU CD 5204).

Description: the posterior part of a dentary with the single most posterior tooth is preserved. The tooth is short, conical and oriented anterodorsally. Its tip has a small, sharp, posteriorly oriented tip. The base of two further teeth is present anteriorly to the last teeth. Considering the large diameter of the tooth traces, these obviously had larger sizes than the last tooth. Resorption pits are present and have circular outlines. In labial view, the bone surface is smooth; it is pierced only by a rather small mental foramen (Fig. 8(x)). In lingual view, the subdental shelf of the dentary is high and has a flat lingual surface. It has the same height along its length; only at the last tooth position does it narrow and project dorsally, terminating behind the last tooth. The Meckelian canal is open; it widens posteriorly. The intermandibular septum is preserved. It has a triangular shape and is located ventrally from the last tooth. The posterior cavity is large. Posteriorly, the ventral margin of the dentary extends ventrally and builds a "cavity" corresponding, most probably, to the articulation surface with the angular. Ventrally from the intermandibular septum, a shallow, distinct, anteroposteriorly directed deepening is visible, corresponding to the surface of the attachment with the splenial. The coronoid process is partially preserved. It shows a thin coronoid facet, which is dorsally broken off.

Remarks: The combination of the following features, characteristic for the family Blanidae (Čerňanský et al. 2016), can be observed on the Çandır dentary: (1) Meckelian groove is open and well-developed; (2) pleurodont teeth; (3) the presence of the splenial (can be assumed based on the available attachment surface). Further characters observable in the Çandir dentary such as (4)) an intermandibular septum extending anteriorly and reaching/surpassing the level of the posterior end of the tooth row; (5) a strong splenial facet in the posteroventral region of the dentary has been mentioned to be charac- teristic for Blanidae and Bipedidae (Folie et al. 2013). Nevertheless, Čerňanský et al. (2016) did not mention either splenial bone or splenial facet to be characteristic for the family Bipedidae. Due to incomplete preservation of the dentary, the number and size of the teeth and mental foramina, which are diagnostic for familiar or generic attribution of the remains (Čerňanský et al., 2016/2017 Herrlingen 11+9), cannot be counted. The presence of slightly posteriorly recurved teeth in the Çandir specimen suggests its attribution to the European Blanus (Čerňanský et al., 2016/2017 Herrlingen 11+9). The comparison of the described specimen with the only known worm lizard from Turkey (Blanus sp., loc. Gebeceler Georgalis et al. 2018) does not reveal any differences. Thus, an assignment of the Çandır dentary to the genus Blanus appears to be possible, but an identification of the material at the family level is preferable.

Lacertilia indet.

Fig. 8(z)

Material: Loc. Karg1 1: one ilium (UU KAR1 1208). Loc. Çandır: one autotomy septa (UU CD 5209).

Description and remarks: The ilium from Karg1 1 is a robust bone; the bone body is thick. The preacetabular process is thick, pointy and oriented posteriorly (Fig. 8(z)). The acetabular fossa has a lunar shape. The morphology of the ilium is typical for lizards (Russell and Bauer 2008). The autotomy septum (UU CD 5209) is small in size and corresponds to the anterior portion. The septum has a trapezoid form and possesses two small and short transverse processes. The morphology of the septum corresponds to the "pattern (b)" or "type 3 of Etheridge" sensu Hoffstetter and Gasc (1969), which is characteristic to, e.g. Teiidae, Lacertidae, Anguidae and some Scincidae. In the locality Çandır, both Lacertidae and Anguidae have been recorded and, most probably, this septum could belong to one of these groups.

Clade Serpentes Linnaeus, 1758

Family Boidae Gray, 1825

Subfamily Erycinae Bonaparte, 1831

Genus Albaneryx Hoffstetter and Rage, 1972

\section{Albaneryx sp.}

Fig. $9(\mathrm{a}-\mathrm{e})$

Material: Loc. Karg1 3: one trunk vertebra (UU KAR3 1204). Description: The vertebra UU KAR3 1204 is fragmentarily preserved; the dia-, para-, pre- and postzygapophyses and condyle are missing. The vertebra, judging by its preserved dimensions, was short $(\mathrm{cl}=2 \mathrm{~mm}(+\sim 0.3 \mathrm{~mm}$ condyle $)$, naw $=$ $2.33, \mathrm{cl} / \mathrm{naw}=0.86(\sim 0.98$ with condyle $))$. The zygosphene facets are rounded. The lateral lobes project slightly dorsally; 

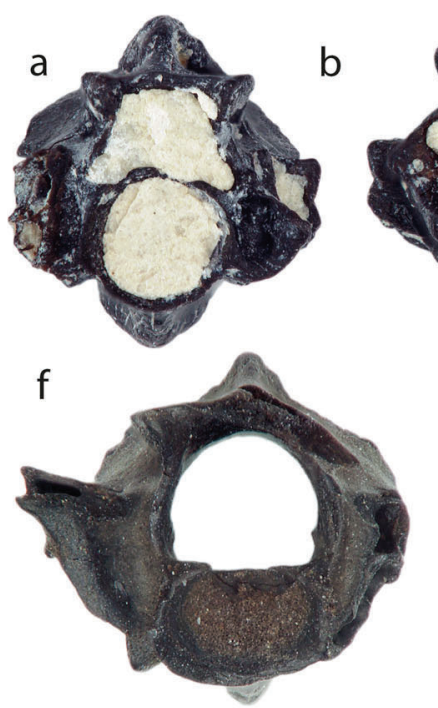

g
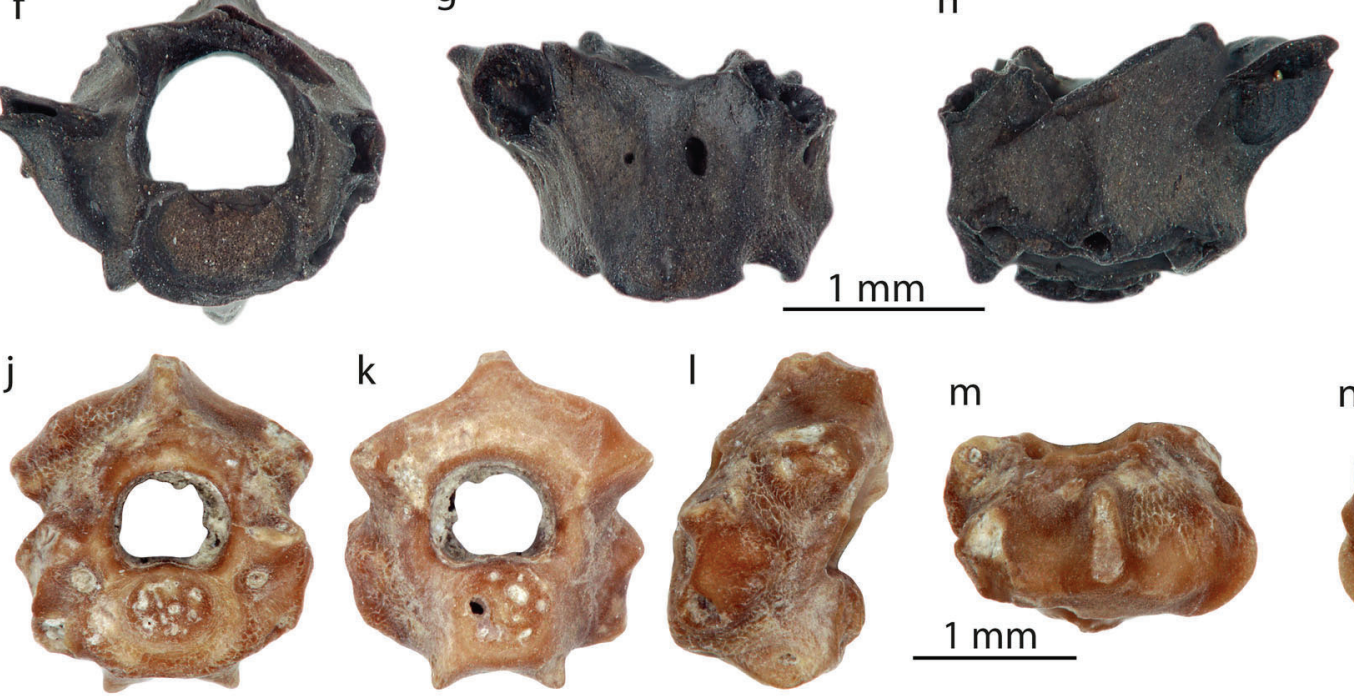

$\mathrm{m}$
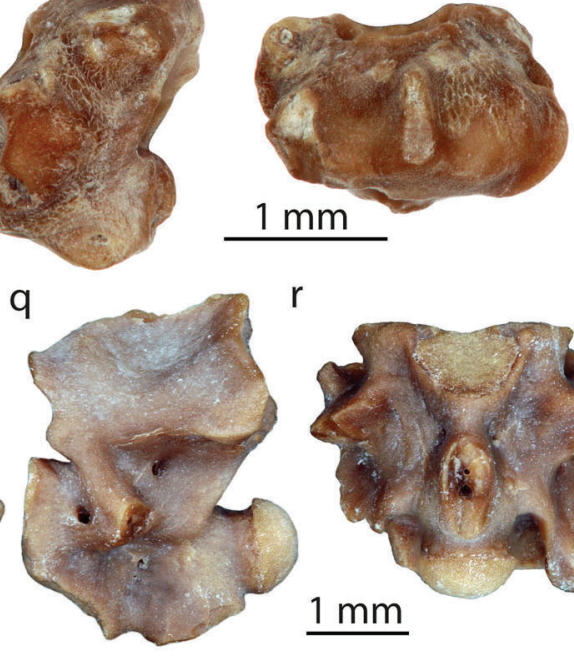

$r$

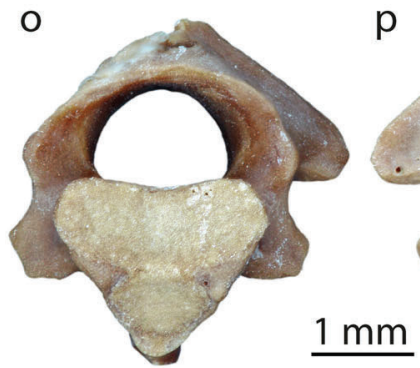

$\mathrm{p}$

$\mathrm{t}$
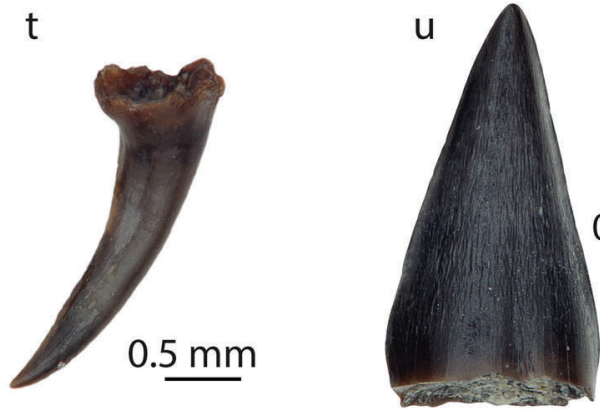

Fig. 9 Snake and crocodile remains from Turkish localities. a-e Trunk vertebra of Albaneryx sp. from loc. Karg1 3 (UU KAR3 1204). f-i Trunk vertebra of Erycinae indet. from loc. Harami 1 (UU HAR1 5200). j-n caudal vertebra of Erycinae indet. from the loc. Bağiçi (UU BAG 1202). o-s Axis of Serpentes indet. from Bağiçi (UU BAG 1204), $\mathbf{t}$ - tooth of

the cranial margin bears a short central lobe (Fig. 9(d)). The neural spine is low and is located at the posterior half of the neural arch. The neural arch is depressed. It arises

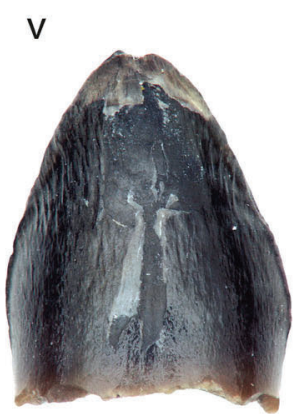
dorsal view, $(\mathbf{e}, \mathbf{n}, \mathbf{r}$ in ventral view
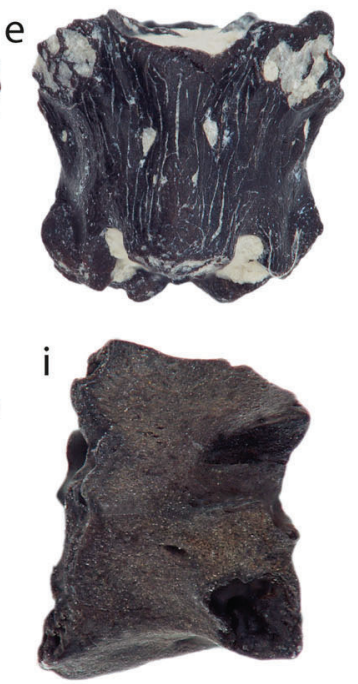

$\mathrm{n}$

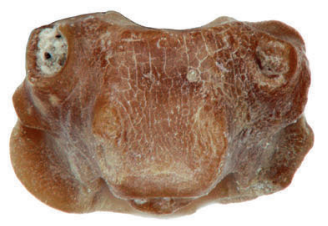

S
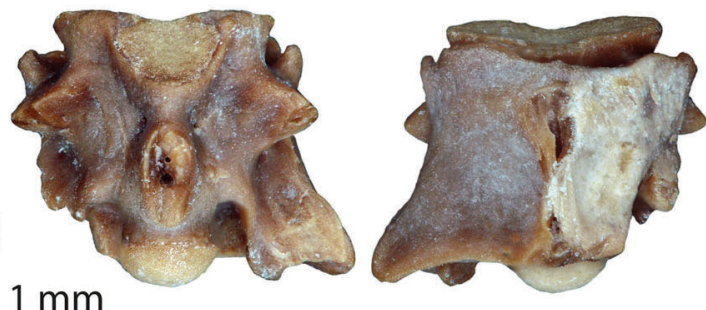

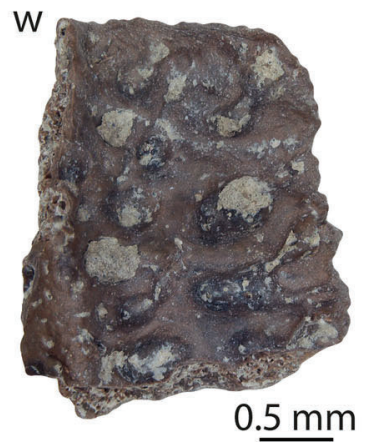

Serpentes indet. from loc. Karg1 1 (UU KAR1 1207). u-w Crocodylia indet. from loc. Karg1 1, teeth $\mathbf{u}-\mathrm{UU}$ KAR1 1202 and $\mathbf{v}$-UU KAR1 1201, w-osteoderm UU KAR1 1204. a, f, j, o Figured in anterior view, $\mathbf{b}, \mathbf{k}, \mathbf{p}$ in posterior view, $\mathbf{c}, \mathbf{i}, \mathbf{l}, \mathbf{q}, \mathbf{t}, \mathbf{u}, \mathbf{v})$ in lateral view, $\mathbf{d}, \mathbf{h}, \mathbf{m}, \mathbf{s}, \mathbf{w}$ in

dorsoposteriorly directly behind the zygosphene and bends caudally after reaching its highest point. In dorsal view, the neural spine is thickened and has a triangular shape. In anterior 
view, the paracotylar foramina are absent (Fig. 9(a)). Deep depressions are present on both lateral sides of the cotyle. The cotyle is round. In ventral view, the vertebral centrum possesses a distinct and well-expressed haemal keel. Two small subcentral foramina are present at both sides of the haemal keel. They are located in anteroposteriorly running subcentral grooves, which extend cranially. The lateral foramina are small and located in the corner (depressions) between the weakly pronounced interzygapophyseal ridge and synapophysis (Fig. 9(c)).

Remarks: The small size of the vertebra $(\mathrm{cl}=2 \mathrm{~mm})$; the absence of paracotylar foramina; the presence of the pronounced haemal keel; depressed neural arch; and low and expanded neural spine allow to attribute the vertebra to the family Erycinae (Ivanov et al. 2018; Rage 1984), excluding the genera Bransateryx and Gongylophis, which have larger vertebra sizes (Szyndlar 1987; Szyndlar and Schleich 1993). UU KAR3 1204 resembles the genus Albaneryx and differs from the genera Eryx and Gongylophis by its thickened neural spine, situated at the posterior half of the neural arch directly behind the zygosphene (Ivanov et al. 2018; Szyndlar and Schleich 1993). Additionally, the vertebra differs from Eryx by the pronounced haemal keel of the vertebra centrum (Szyndlar 1991; Blain 2016). Further vertebra comparison with species of the genus Albaneryx is difficult due to the poor preservation of the bone.

Family Erycinae Bonaparte, 1831

Erycinae indet.

Fig. $9(\mathrm{f}-\mathrm{n})$

Material: Loc. Harami 1: one trunk vertebra (UU HAR1 5200). Descriptions and remarks: the vertebra UU HAR1 5200 (Fig. 9(f-i)) is smaller than the UU KAR3 1204 (Albaneryx sp.) (Fig. 9(a-e)), its centrum length (cl) equals $1.29 \mathrm{~mm}(+\sim$ $0.2 \mathrm{~mm}$ condyle). The vertebra is wide (naw $=1.62 \mathrm{~mm}$ ) than long, $\mathrm{cl} / \mathrm{naw}=0.8$ (0.92 with condyle). In anterior view, the neural arch is high and has a rounded outline. The cotyle is incomplete. The paracotylar foramina are absent in the broad depressions on both sides of the cotyle (Fig. 9(f)). In lateral view, the vertebrae centrum bents posteroventrally and possesses a weakly pronounced haemal keel. The preserved anterior portion of the neural spine is low and rises slightly posteriorly (Fig. 9(i)). In dorsal view, the right lateral lobe of the zygosphene is observable. Also, in dorsal view, the neural spine arises not directly behind the zygoshene, but slightly posteriorly (Fig. 9(h)). In ventral view, two subcentral foramina are present laterally on both sides of the haemal keel in the anterior half of the vertebra centrum (Fig. 9(g)). The small vertebra sizes, cl/ naw $<1$ and the absence of the paracotylar foramina suggest the assignment of the vertebra to the subfamily Erycinae (Szyndlar 1991). UU HAR1 5200 can be distinguished from UU KAR3
1204 (Albaneryx sp.) by its smaller size, less developed haemal keel and shorter neural spine. Thus, this vertebra can be considered to be belonged to a different taxon than Albaneryx sp. However, the poor preservation of the vertebra does not allow any further identification.

Material: Loc. Bağiçi: one caudal vertebra (UU BAG 1202). Descriptions and remarks: The preserved caudal vertebra is fragmentarily preserved. Its surface is eroded. The vertebra is small, with a long vertebra centrum $(\mathrm{cl}=1.13 \mathrm{~mm})$ and a lower naw value equalling $0.96, \mathrm{cl} / \mathrm{naw}=1.19$. Prezyg-, postzyg, haem- and pleurapophyses are broken.

In anterior view, the neural canal is small and rounded. The cotyle is anterodorsally flattened. The paracotylar depressions are deep and possess paracotylar foramina (Fig. 9(j)). The neural arch rises posteriorly. The neural spine is broken, but, based on its preserved portion, it can be assumed to have been high (Fig. 9(k)). In dorsal view, the neural spine is short and arises behind the zygosphene (Fig. 9(n)). The small size of the vertebra and its dimensions suggest its assignment to subfamily Erycinae (Szyndlar 1991). Its further identification, however, is difficult, due to its poor preservation.

Serpentes indet.

Fig. $9(0-t)$

Material: Loc. Karg1 1: one tooth (UU KAR1 1207). Loc. Karg1 3: two vertebrae (UU KAR3 1203, 1205, 1206). Loc. Keseköy: one tooth (UU KE 5218). Loc. Bağiçi: one axis (UU BAG 1204).

Descriptions and remarks: the preserved teeth are conical and posteriorly oriented. UU KAR1 1207 has sharp tip without any canal (Fig. 9(t)).

The preserved axis (UU BAG 1204) lacks the posterior (third) intercentrum (hypapophysis), transverse process and neural spine. The odontoid process is flattened anteriorly, with two clear articulation surfaces (Fig. 9(o)). Ventrally from the odontoid process, the anteroventrally exposed articulation surface of the second intercentrum is visible. The vertebra centrum between the second and third intercentra is concave. The neural arch is long. In posterior view, the roof of the neural arch is shaped as a dorsally flattened triangle. The postzygapophysis is nearly horizontally oriented (Fig. 9(q)). The posteroventral corners of the neural arch, located above the postzygapophyses, possess weakly pronounced posteriorly oriented processes. The articulation surface of the zyngatrum is oriented at about $45^{\circ}$. The observed morphology of the preserved axis resembles mostly that of the natricin snakes (the weakly pronounced posterior processes of the neural arch, long axis) (Szyndlar 1991). However, due to lack of the comparative material of other groups we prefer to classify the axis as Serpentes indet.

Three further vertebrae (UU KAR3 1203, 1205, 1206) are very fragmentarily preserved, which makes any identification impossible. 
Table 2 Fauna of ectothermic vertebrates from the studied localities. Orange cells — results of the present study, green cells — Čerňanský et al. 2017

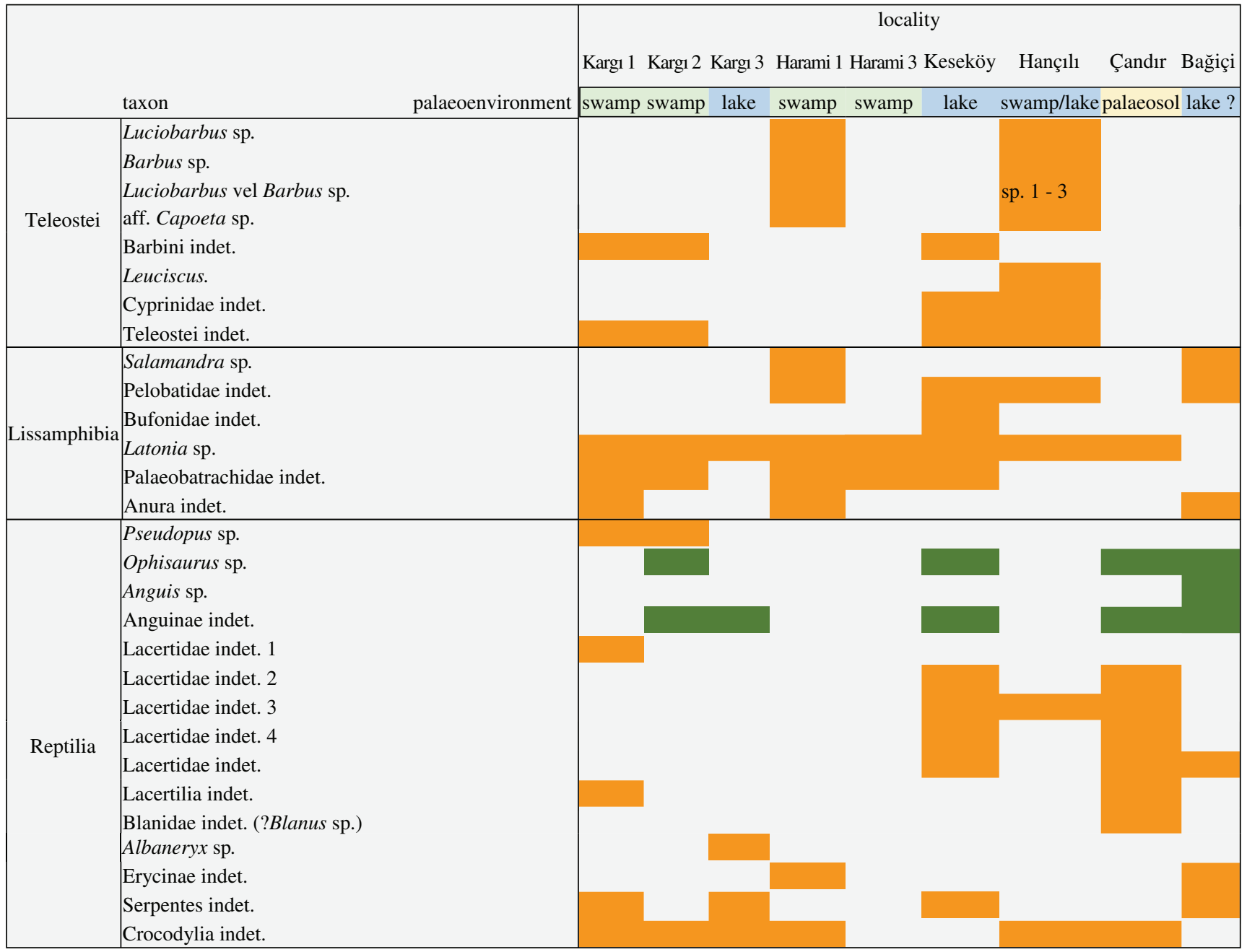

Crocodylia Gmelin, 1789

Crocodylia indet.

Fig. $9(\mathrm{u}-\mathrm{w})$

Material: Loc. Karg1 1: 78 teeth (UU KAR1 1200-1202), four osteoderms (UU KAR1 1203, 1204). Loc. Karg1 2: 97 teeth (UU KAR2 1200). Loc. Karg1 3: five teeth (UU KAR3 1201). Loc. Harami 1: six teeth (UU UU HAR1 5202). Loc. Hancili: 49 teeth (UU KE 5201). Loc. Çandır: one tooth (UU CD 5205)

Description and remarks: All studied teeth belong to smallsized individuals. They are lingolabially compressed and conical in shape. They are represented by different morphologies from slender, high and narrow to rather blunt, short and broad. At their bases, they show a crown-root construction. Both the lingual and labial tooth surfaces possess weakly pronounced striae (Fig. 9(u, v)). The mesial and distal cutting edges possess sharp cutting edges. The fragments of osteoderms display the characteristic ornamentation for crocodiles composed of deep rounded well-pronounced pits (Fig. 9(w)).

\section{Discussion}

Collectively, the fish, amphibian and reptilian faunal record of the Karg1 1, Karg1 2, Karg1 3, Harami 1, Harami 3, Hancil, Keseköy, Çandır and Bağiçi localities is diverse (Table 2) and contains carps (Luciobarbus sp., Barbus sp., Luciobarbus vel Barbus sp., aff. Capoeta sp., Barbini indet., Leuciscus sp.), a salamander (Salamandra sp.), anurans (Bufonidae indet. (? Pseudepidalea sp.), Pelobatidae indet., Latonia sp., Palaeobatrachidae indet.), lizards (Pseudopus sp., Lacertidae indet. 1, Lacertidae indet. 2, Lacertidae indet. 3, Lacertidae indet. 4, Blanidae indet. (? Blanus sp.)), snakes (Albaneryx 
sp., Erycinae indet.) and crocodiles (Crocodylia indet.). However, each individual locality yielded only a very limited number of taxa. In addition to this, all studied samples are represented by small, disarticulated bones and skeletal fragments. Fossil remains of some groups, such as turtles and tortoises, are not found in the samples. In this light, the assemblages reported here are unlikely to represent complete reconstructions of palaeoherpetological assemblages, due to both sampling (sediment washing and subsequent screening which resulted in sampling bones of just certain size range) and taphonomic biases. Consequently, our palaeobiogeographic and palaeoecological inferences are tentative.

\section{Cyprinids}

The identifiable fish material from the studied localities belongs to the family Cyprinidae. Only the locality Hancill provided leuciscin remains; the other localities contain abundant remains of barbin fishes (Table 2). The fish remains from the studied oldest localities (Karg1 1, Karg1 2, Keseköy, latest Oligocene to early Miocene) can be assigned to a small-sized barbin. The observed tooth morphology cannot be referred to any fossil form known from Eurasia. Most probably, they could represent an ancient, extinct barbin group. Both the Harami 1 and Hancilı localities provide remains of two widely distributed barbin genera, Luciobarbus and Barbus. Indeed, the barbin record from Hancilı, which is identified by isolated pharyngeal teeth as Barbus sp. and Luciobarbus sp., could include three different barbin taxa, even if considering only three different morphologies of the serrated rays of the dorsal fin. However, this cannot be stated with confidence due to the lack of comparative osteological studies of this element in the extant barbin species.

The Harami 1 locality (22.2 Ma) provides the oldest known remains for both genera Barbus and Luciobarbus. So far, the oldest record of the genus Luciobarbus was known from the earliest late Miocene of Austria (loc. Mataschen, Schultz 2004). Böhme and Ilg (2003) mentioned the oldest Luciobarbus from Turkey, from the size contemporaneous to Mataschen. However, this material stays unfigured. We suggest that Barbus sp. from Harami 1 as well as Hancil should be considered the oldest representatives of this genus, since earlier publications describing Barbus sp. do not represent the genus Barbus sensu Yang et al. (2015). Our finds would provide important information also for the calibration of the molecular trees with minimum age for the estimate of the origination of different barbin clades (by 22.2 Ma), i.e. Luciobarbus + Barbus, or separately for both Luciobarbus and Barbus sensu Yang et al. (2015).

\section{Amphibians}

The only caudate taxon from the studied Anatolian sites is Salamandra sp., recovered from the localities Harami 1 and Bağiçi. It is the first fossil record of the genus in this region.
The genus is well-known from the Neogene of Europe, but its out-of-Europe occurrence was hitherto unknown. Our record provides evidence of caudate amphibians in Anatolia as early as in the earliest Miocene and at least during the middle Miocene. Because of the absence of osteological data on the genus Salamandra, it is impossible to decide whether this fossil is related to the recent species Salamandra infraimmaculata distributed in Anatolia and the Middle East. Until now, the fossil record of caudates in Anatolia was represented by imprints of Salamandridae indet. from the locality Ağaöz, early Miocene (Paicheler et al. 1978) which, however, cannot be compared with our specimens. The caudate from Ericek (van den Hoek Ostende et al. 2015) resembles a frog maxilla and should be revised critically.

Hitherto, only few fossil anuran taxa have been reported from Anatolia, mainly from the early and middle Miocene (Table 1). They include brown frog (Rana), green frogs (Pelophylax, originally described as Rana sp. in Paicheler et al. (1978)) and spadefoot toad (Pelobates sp.). The evidence of Pelobates is based on premetamorphic tadpoles (Paicheler et al. 1978; Dubois et al. 2010) in which, however, it is difficult to decide whether they belong to Pelobates or Eopelobates. Similarly, Wassersug and Wake (1995) reported on two tadpoles from the middle Miocene of Gürcü (not included in Table 1) that they have assigned to Pelobates sp.

The discovery of remains of the genus Latonia in nearly all of the studied localities (Table 2) suggests the presence of this genus in central Anatolia from the latest Oligocene to the middle Miocene. The remains represent small-to-large individuals (e.g. Fig. 4). The oldest record of the genus is known from the earliest Oligocene of Europe (e.g. localities Grafenmühle 10, Möhren 12 and 13; Böhme and Ilg 2003). Their appearance in Europe coincides with the Grande Coupure event, during which the vertebrate fauna of Europe has been replaced by new arrivals including large and small mammals (Legendre 1989; Hooker 2010), as well as amphibians and reptiles (Rage 2012; Vasilyan 2018). Whether Latonia invaded Europe (e.g. via Anatolia) or evolved in Europe from some other discoglossoids by means of heterochrony (potentially supported by the observation that Latonia is sometimes accompanied by discoglossoid anurans of smaller size which, although being adult, correspond to early developmental stages of Latonia) can be only hypothesised. Discoglossus troscheli from the Oligocene and Opisthocoelellus weigelti and $O$. hessi from the Eocene and Oligocene of central Europe, or Eodiscoglossus, Iberobatrachus, Bakonybatrachus or Paralatonia from the Cretaceous of Spain, Hungary and Romania (see literature summarised in Roček 2013) further illustrate this possibility.

Considering the relative uniformity of species within the genus Palaeobatrachus and the fact that the majority of these were based on articulated skeletons, disarticulated bones of the Palaeobatrachidae usually provide only limited 


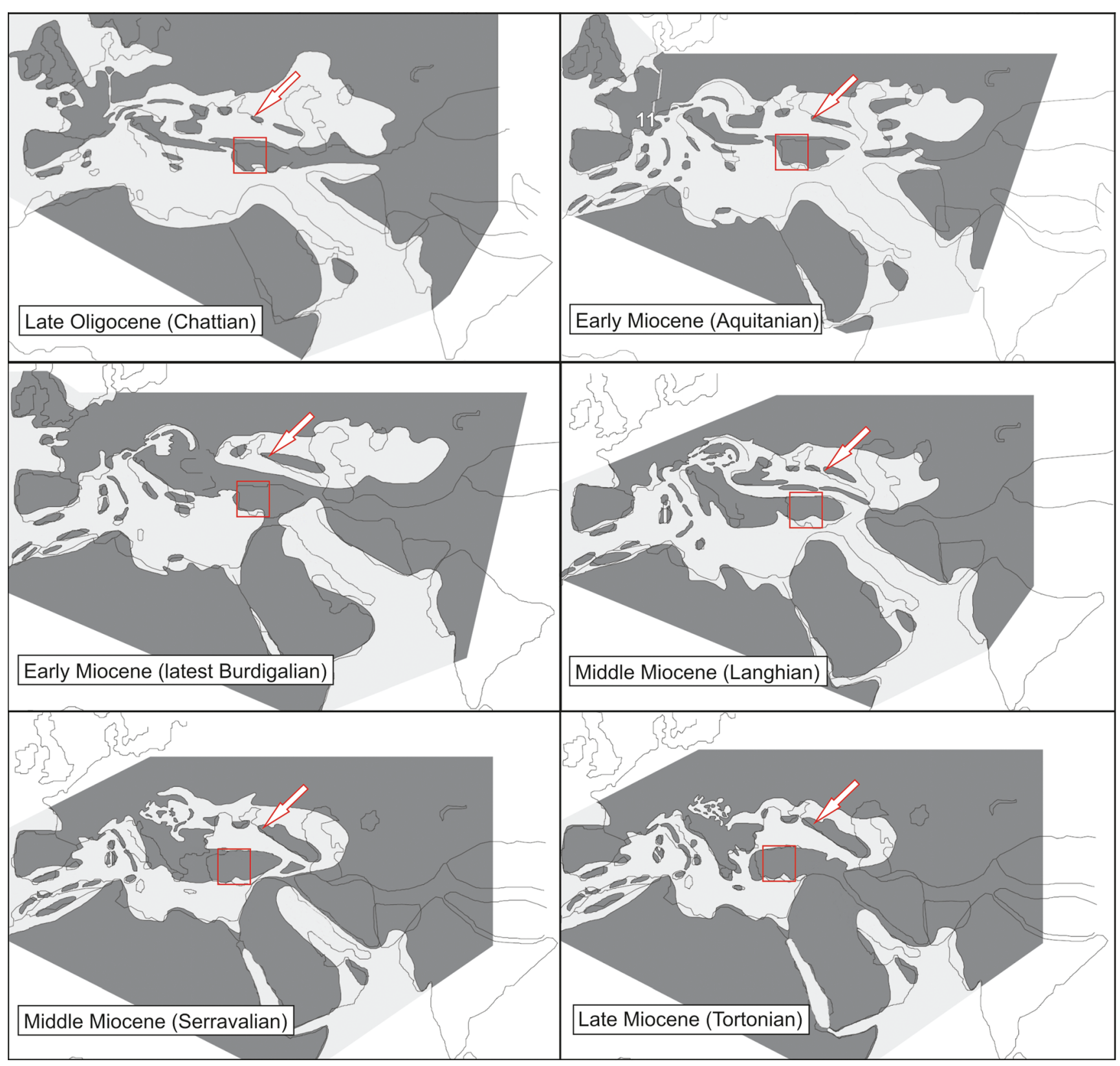

Fig. 10 Palaeogeographic relations of Anatolia (marked by red square) to Europe between late Oligocene and late Miocene. Noteworthy is permanent isolation of the area in northern Caucasus (marked by red

arrow) where Palaeobatrachus was reported by Syromyatnikova (2018), which means that immigration from the main area of distribution had to occur relatively quickly. Maps are from Rögl (1999)

information for taxonomic assignments. However, the material described here is an exception. The earliest palaeobatrachids were recorded from the Cretaceous of the Iberian Peninsula, and from here, they likely spread to the central and eastern part of Europe in Eocene and post-Eocene times (Wuttke et al. 2012). Considering that paleobatrachids are known from Europe with only a few exceptions, one of them being Anatolia), it is likely that the palaeobatrachids from Anatolia had their origin in pre-Miocene Europe and that they are not immigrants from Asia (Fig. 10). An interesting problem associated with Anatolian Miocene occurrences of palaeobatrachids is the record of Palaeobatrachus from the locality Gaverdovsky in the northern Caucasus (Tesakov et al. 2017, Syromyatnikova 2018). Contact between this region and the main area of pre-Miocene distribution of palaeobatrachids in Europe was probably available during a very short window of time (Fig. 10).

The remains of Pelobatidae indet. from Harami 1, Keseköy and Bağiçi provide new data on the early Miocene record of the family in Anatolia. Earlier, tadpoles assigned to Pelobates sp. were described from the early Miocene localities Ağaöz and Ahlath Dere (Paicheler et al. 1978; Dubois et al. 2010) 
and from the early Miocene of Gürcü Valley (Beşkonak and Akoz (Agaöz) sites) (Wassersug and Wake 1995). The former two localities are situated in the Beşkonak sequence of lacustrine origin of the Dereköy piroclasts, at the base of the Güvem Formation (Paicheler 1978). The locality Keseköy is also in the Beşkonak sequence (Yavuz-Ișik 2008). The age of the sequence has been dated using the radiometric analysis between 19.7 Ma (underlaying Çukurviran dacite) and 17.9 Ma (overlaying Bakacak andesite) (Wilson et al. 1997; Yavuz-Ișık 2008; Denk et al. 2017). Pelobatidae indet. from the locality Harami 1 represents the oldest record (early early Miocene, 22.2-22.3 Ma) of the family in Anatolia, whereas the Bağiçi specimen represents the youngest (late middle Miocene) form of the family in Anatolia known to this date.

At first sight, the frontoparietals from Hancilı differ in their overall appearance from those of recent pelobatids, which are coalesced. However, when the development of the frontoparietal in Eopelobates and Pelobates (both recent and fossil) is followed (Roček 1981; fig. 43; Maus and Wuttke 2004; Roček and Wuttke 2010; fig. 8; Roček et al. 2014; fig. 11-n), we see that the frontoparietal takes its origin from a pair of bones that come into contact along the midline at a later stage. In addition, another, unpaired median ossification arises posteriorly and inserts into the wedge-like space between the posterior parts of both frontoparietals. It is only during metamorphosis when all three parts fuse into a single frontoparietal complex. It has been discovered recently that the developmental scheme of the tripartite pelobatid frontoparietal may persist until adulthood in some taxa (e.g. Eopelobates deani; Roček et al. 2014; fig. 4c). Arrested development of the frontoparietal in some extinct pelobatids may, therefore, be taken as a case of heterochrony. Our frontoparietals, which appear to represent adult individuals, could have been parts of a larger complex, as seems to be supported by the frontoparietal incrassation on the inner surface of the bones reaching their medial margin (i.e. the incrassation extended onto the opposite frontoparietal). The same holds for the posteromedial margin of the bone, which can be taken as an evidence that the incrassation extended onto the ventral surface of the posteriorly unpaired element. Pelobatidae were restricted to Europe for the whole period of their existence, even if their earliest representatives probably invaded Europe from North America in the early Eocene (Roček et al. 2014; Wang et al. 2017). One may speculate that heterochrony could have been a response to conditions in the marginal areas of distribution, such as present-day Anatolia. Whereas isolated bones of adults and of the mentioned fossil tadpoles may be considered unequivocal evidence of the Pelobatidae, their generic assignment (either to the genus Eopelobates or Pelobates) is more difficult. It was already mentioned above (see Description) that the maxillae differ in the shape of their zygomaticomaxillar process, which is almost pointed and inclined posteriorly in UU KE 5006 (Fig. 4(q, r)) and probably also in UU HAR1 5051 (Fig. 4(m, n)), whereas the maxilla in UU BAG 1001 (Fig. 4(o, p)) is different - its zygomaticomaxillar process is divided in two parts (which means that its contact with the squamosum was longer than in Pelobates); the maxilla had its articulation with pterygoid by means of a deep, but not prominent horizontal lamina instead of the processus pterygoideus and the sculpture on its labial surface is of the pit-and-ridge type. All these characters point to Eopelobates. This is also supported by the tripartite frontoparietal, only moderately extended laterally (Fig. 4(s-v)). Thus, it is possible that representatives of both genera occurred in Anatolia, or at least some sort of transitional form between them, as was found, e.g. in Grytsiv (Roček et al. 2014). However, the occurrence of pelobatid tripartite frontoparietals from Anatolia (Fig. 4(s-v)) does not necessarily mean that they represent pelobatids closely related to $E$. deani. Rather, they could support the view that some characters, such as those associated with rate of development, could evolve independently in forms distant both geographically and chronologically.

Regarding the tadpoles, their generic assignment is also not easy. Tadpoles of Eopelobates have the posterior part of the parasphenoid covered with sculpture, whereas it is smooth in Pelobates. Such details, however, are not discernible in our tadpoles, so their generic assignment remains open.

The true toad record has very limited stratigraphic occurrence in our samples. It has been only found in the locality Keseköy (Table 2). In Claessens (1996, 1997), it has been referred to the genus Bufotes, but after critical revision, we refer it to Bufonidae indet. Whether Bufotes has entered from Asia to Europe via Turkey as suggested earlier (Claessens 1997; Vasilyan et al. 2017), we cannot state with absolute confidence here. Further finds from early Miocene localities could shed more light on this palaeobiogeographic question.

Surprisingly, the samples from our studied localities do not contain any ranid remains, which, however, may be a result of limited sampling or taphonomic bias.

\section{Lizards}

Pseudopus sp. from the localities Karg1 1 and Karg1 2 represents the first and oldest known record of the genus from Anatolia and entire Eurasia. So far, Pseudopus was known exclusively from Europe since the earliest Miocene until the late Pleistocene (Klembara et al. 2010; Čerňanský et al. 2015; Klembara and Rummel 2018). The oldest European record of the genus (Pseudopus aff. ahnikoviensis) has been described from the locality Wiesbaden-Amöneburg, Germany, of a Late Aquitanian age (21-22 Ma) (Čerňanský et al. 2015). Thus, Pseudopus sp. from two studied Turkish localities Karg1 1 and Karg1 2 of the latest Oligocene and latest Oligocene-earliest Miocene (earliest Aquitanian) age, respectively, can be considered to represent the earliest documented remains of the genus from Eurasia. Taking into account the European and Anatolian records of the genus, we hypothesise that the genus, being present in Anatolia during the latest Oligocene and earliest Miocene, could have migrated 
into Europe during the early Miocene from Anatolia. Our hypothesis is contrary to Klembara and Rummel (2018) who presuppose the opposite - a west-to-east migration of the genus. Considering the present finds, the probable origin of the genus in Anatolia and its later dispersal across land bridges can be suggested. However, the timing of this event stays unclear, since the European record is scarce and restricted to Central Europe. Further finds from Eastern and Southern Europe will be necessary to trace the migration routes of this genus.

The lacertid lizards are represented by at least four forms in the studied localities. Lacertidae indet. 1 is the oldest (latest Oligocene, loc. Karg1 1) form. Lacertidae indet. 2 and Lacertidae indet. 3 occur in late early Miocene and/to middle Miocene localities (Keseköy, Hancılı, Çandır), whereas Lacertidae indet. 4 is known only from the middle Miocene locality Çandır. Lacertidae indet. 1 and Lacertidae indet. 3 have tooth morphologies well-known from numerous Neogene localities of Europe, but forms with an overall morphology (shape of bone and teeth) comparable with that of Lacertidae indet. 1 cannot be found. We suggest that Lacertidae indet. 3 from loc. Keseköy and Çandır represents a fossil form of recent Western Asian genera, like Darevskia, Algyroides, indicating the presence of this group in the region already since the early Miocene.

Until recently, worm lizards were completely unknown from the Anatolian fossil record. A fossil form of the Blanus strauchi complex has been newly described from the middle Miocene (13.6 Ma) Gebeceler locality in western Turkey (Georgalis et al. 2018). Here, we report another Anatolian worm lizard (Blanidae indet. (?Blanus sp.)) record from the Çandır locality, which has comparable or slightly older age than the Gebeceler fossil. Our find suggests that this lizard group was distributed in the middle Miocene much more northern and eastern from both their known fossil and recent distribution areas. This provides an excellent example that the reptilian fossil record of Anatolia is understudied and numerous important fossil finds are still waiting to be uncovered.

\section{Snakes}

Among the scarce snake finds, the most interesting is the vertebra referable to the genus Albaneryx (Albaneryx sp.) from the locality Karg1 3 (earliest Miocene). Until now, the stratigraphic record of this genus covered a very short time period (several few million years) from the middle Miocene to the earliest late Miocene of Europe and Western Asia (Böhme and Ilg 2003; Ivanov et al. 2018). The oldest record of the genus is known from the middle Miocene (13.5-13.7 Ma) locality Sansan (Augé and Rage 2000), whereas the youngest record is documented from Grytsiv, Ukraine (11.1 Ma) (Zerova 1989). Considering the morphological similarities of Albaneryx with the North American genus Lichanura, it has been hypothesised (Zerova 1989; Augé and Rage 2000) that the genus arrived in Europe from Northern America via Asia. However, no evidences for this hypothesis have been provided and the appearance of the genus in Europe stays still enigmatic.

Interestingly, the oldest record of Albaneryx coincides with the end of the Miocene Climatic Optimum (MCO) (loc. Sansan), when a significant temperature drop has been observed (Zachos et al. 2001; Böhme 2003). The new early Miocene find of the genus from central Anatolia favours the hypothesis of their arrival from Asia into Europe, which was, most probably, linked to particular climatic conditions necessary for their dispersal and life, prevailing in Europe after the MCO.

Further finds of small-sized erycins from the localities Harami 1 and Bağiçi suggest the (fairly continuous) presence of this groups in the Neogene fossil record of central Anatolia. More fragmentarily preserved snake material (Table 2, Serpentes indet.) is available from the studied localities, but too poorly preserved for any further consideration.

\section{Crocodiles}

Crocodile remains in five studied localities suggest their presence (with some gaps) in central Anatolia from the latest Oligocene (Karg1 1) to the middle Miocene (Çandır) (Fig. 1, Table 2). So far, fossil crocodiles (Diplocynodon sp.) are known from the early early Miocene of eastern Turkey (loc.Tuz-6, Turabi Formation) (Sen et al. 2011) and mid Oligocene-mid Miocene of western Turkey (Küçükdoganaca Kökü) (Schleich 1994). However, since identifications based on tooth material cannot be made with confidence (Delfino 2002), these fossils should be considered Crocodylia indet. As suggested by Böhme (2003), the presence of crocodiles suggests a warm climate with a mean annual temperature not lower than 15.7 ${ }^{\circ} \mathrm{C}$, minimal cold and warm month temperatures no lower than $-1.7^{\circ} \mathrm{C}$ and $18.3^{\circ} \mathrm{C}$, respectively.

\section{Palaeoenvironmental interpretations}

We tentatively reconstructed palaeoenvironments of the localities, taking into account both depositional environments of the fossiliferous horizons and the assemblage of ectothermic vertebrates. The fossil faunas of Karg1 1 is found from black clays rich in organic material; Karg1 2-most probably from comparable sediments as in Karg1 1; Karg1 3-from greyish clays rich in diatomite; Harami 1 -from darkish clay/coal; Harami 3-from a layer of fine laminated coal (Claessens 1996); Keseköy - from green-brown, partly laminated clays and marly clays (Krijgsman et al. 1996; Yavuz-Ișık 2008); Hancilı - from fine laminated clays and coal (Kaymekci 2000). The depositional palaeoenvironment of the sites Karg1 1, Karg1 2, Harami 1, Harami 3 and Hanc1lı can be interpreted as swamp or marsh, whereas for Karg1 3 and Keseköy a lacustrine environment is characteristic. Hancilı deposits suggest a mix of lake and swampy environment. 
The fossil fauna of Çandır is yielded from reddish silts (Krijgsman 2003) that likely represent pedogenically modified package of the coastal lagoons or lake margins. The sedimentology of the Bağiçi locality is unknown, but a lacustrine environment has been suggested (Claessens 1996).

Palaeoenvironmental reconstructions for the studied localities, taking the assemblages of ectothermic vertebrates into account, reflect a mosaic of different environments. In Karg1 1 and 2 , an environment that transitions from water (Barbini indet., Palaeobatrachus sp., Crocodylia indet.) to (wet) nearshore (semi-terrestrial Latonia sp.) and terrestrial open habitats (Pseudopus sp., Ophisaurus sp., Lacertidae indet. 1) is suggested. The few fossil remains from Karg 3 suggest the presence of a body of water (Crocodylia indet.) with surrounding sandy (Albaneryx sp.), wet nearshore (Latonia sp.) areas, whereas in Harami 3 water body (Palaeobatrachus sp.) and wet nearshore areas (Latonia sp.) is suggested. Among the studied localities, Harami 1 represents the most diverse palaeoenvironment encompassing aquatic habitats (Luciobarbus sp., Barbus sp., Palaeobatrachus sp., Crocodylia indet.), nearshore areas (Latonia sp.) with sandy soils (Pelobatidae indet., Erycinae indet.) and forested areas (Salamandra sp.). The Keseköy assemblage of ectothermic vertebrates suggests the presence of an aquatic environment (Barbini indet., Palaeobatrachus sp.), surrounded by nearshore habitats (Latonia sp.) with sandy soils (Pelobatidae indet.) and large areas with open stony areas (Bufonidae indet., Ophisaurus sp., Laceridae indet. 1 and 2). The Hancill locality is dominated by aquatic groups (at least three barbins, Leuciscus sp., Crocodylia indet.), but groups inhabiting nearshore areas (Latonia sp.) with sandy soils (Pelobatidae indet.) and open habitats (Lacertidae indet. 3) were also present. The Çandır association is dominated by terrestrial heliophile groups such as Ophisaurus sp., Lacertidae indet. 1, Lacertidae indet. 2 and Lacertidae indet. 3, but also aquatic (Crocodylia indet.), semiterrestrial (Latonia sp.) and woodland (Blanidae indet. (?Blanus sp.)) forms were also present. The herpetofaunistic assemblage of the Bağiçi locality suggest a terrestrial environment with sandy cover (Pelobatidae indet., Erycindae indet.), forested area (Salamandra sp., Anguis sp.) and open habitats (Ophisaurus sp., Laceridae indet.).

\section{Conclusions}

The results of the present study significantly enlarge the knowledge of the fish, amphibian and reptilian fossil record of Anatolia and shed more light on the palaeobiogeographic significance of Anatolia for the distribution of these vertebrate groups.

Earlier studies of the Anatolian fish record documented several species of the genera Leuciscus, Barbus and Tinca from the early Miocene (to middle Miocene) (Table 1). However, the fossil material was assigned to a specific genera based on cranial and postcranial bone characteristics and did not include the characters of the pharyngeal dentition. This precludes comparison with fossil material from our study and vice versa. More studies and better material are necessary to provide data for linking the cyprinid taxa identified by the pharyngeal teeth and other skeletal elements.

Previously, four different taxa of early-to-middle Miocene amphibians have been documented in the Anatolia record (Table 1). Our present study found two comparable groups (Salamandra sp. and Pelobatidae indet.) and added three more taxa (Latonia sp., Palaeobatrachus sp. and Bufonidae indet.). Frog taxa reported earlier, namely green (Pelophylax sp.) and brown frogs (Rana sp.), have not been documented in our study.

Until recently, no fossil lizards have been recorded from Anatolia. Čerňanský et al. (2017) and Georgalis et al. (2018) have reported first anguids and amphisbaenan from Turkey. The studied localities provided addition lizard material, such as the oldest Pseudopus record, diverse lacertids (Lacertidae sp. 1-4). The previously known snake record from Turkey is limited to Colubroidea indet. and Bavarioboa sp. (Table 1). As Szyndlar and Hoşgör (2013) have suggested, the find of Bavarioboa sp. forms a link between terrestrial faunas of Asia and Europe. Our find of Albaneryx sp. provides an additional support for this hypothesis.

In summary, the latest Paleogene and middle Miocene fish, amphibian and reptilian fauna of central Anatolia is represented by the following groups: Barbini, Leuciscinae, Salamandridae, Pelobatidae, Bufonidae, Alytidae, Palaeobatrachidae, Ranidae, Anguinae, Lacertidae, Amphisbaenia, Erycinae, Boinae, Chelydridae and Crocodylia. All these groups are broadly known in the fossil record of Europe and suggest strong link between European and Anatolian ectothermic faunas. The present study provides a clear example of the important role of Anatolia in the dispersal of non-mammalian vertebrate groups. It also underscores the informative value of relatively poor fossil samples. Further studies on the Anatolian fossil record will undoubtedly provide further important clues to the understanding of the formation of the European fossil record.

Acknowledgements We would like to thank Wilma Wessels (University Utrecht) for support and providing all necessary details about the studied material and locality. We would like to acknowledge Sevket Sen for the information about the Hancilı locality. We also thank the reviewers (Andrea Villa, Olga Otero and an anonymous reviewer), whose critical comments improved the manuscript. We would like to address our special thanks to the guest editor of this special issue - Lars van den Hoek Ostende - as well as to the managing editor of the journal Sinje Weber, whose comments and suggestions significantly improved the manuscript.

Funding information The contribution by ZR was funded by the research plan of the Institute of Geology of the CAS (RVO67985831).

\section{Compliance with ethical standards}

Conflict of interest The authors declare that they have no conflicts of interest. 


\section{References}

Arratia, G. (2000). New teleostean fishes from the Jurassic of southern Germany and the systematic problems concerning the 'pholidophoriforms'. Paläontologische Zeitschrift, 74, 113-143. https://doi.org/10.1007/BF02987957.

Augé, M. L., \& Rage, J.-C. (2000). Les Squamates (Reptilia) du Miocène moyen de Sansan. Mémoires du Muséum national d'histoire naturelle, 183, 263-313.

Ayvazyan, A., Vasilyan, D., \& Böhme, M. (2018). 3D morphology of pharyngeal dentition of the genus Capoeta (Cyprinidae): implications for taxonomy and phylogeny. Journal of Zoological Systematics and Evolutionary Research, 255, 179-190. https://doi. org $/ 10.1111 /$ jzs. 12217 .

Blain, H.-A. (2016). Amphibians and squamate reptiles from Azokh 1. In T. King, L. Yepiskoposyan, \& P. Andrews (Eds.), Y. Fernandes Jalvo (pp. 1-20). Azokh Caves and the Transcaucasian Corridor: Springer Verlag.

Blain, H.-A., Gibert, L., \& Ferràndez-Cañadell, C. (2010). First report of a green toad (Bufo viridis sensu lato) in the Early Pleistocene of Spain: palaeobiogeographical and palaeoecological implications. Comptes Rendus Palevol, 9, 487-497.

Bleeker, P. (1859). Enumeratio specierum piscium hucusque in Archipelago indico observatarum, adjectis habitationibus citationibusque, ubi descriptions earum recentiores reperiuntur, nec non speciebus Musei Bleekeriani Bengalensibus, Japonicis, Capensibus, Tasmanicisque. Neerlandense, 6, 1-276.

Böhme, M. (2003). The Miocene climatic optimum: evidence from ectothermic vertebrates of Central Europe. Palaeogeography Palaeoclimatology Palaeoecology, 195, 389-401.

Böhme M., \& Ilg A. (2003). fosFARbase. Available at www.wahrestaerke.com. Accessed 1 December 2015.

Böhme, M., \& Vasilyan, D. (2014). Ectothermic vertebrates from the Late Middle Miocene of Gratkorn (Austria, Styria). In M. Böhme, M. Gross, \& J. Prieto (Eds.) The Sarmatian vertebrate locality Gratkorn, Styrian Basin. Palaeobiodiversity and Palaeoenvironments, 94(1), 21-40.

Böhme M., Reichenbacher B., \& Schulz-Mirbach T. (2003). Neogene freshwater fishes from Anatolia-a key for understanding the (palaeo-)biogeography of European freshwater fishes. I. K. Oray, M. S. Çelikkale, G. Özdemir (Ed.) International Symposium of Fisheries and Zoology, p unknown.

Bonaparte, C. L. (1831). Saggio di una distribuzione metodica degli animali vertebrati. Rome: Antonio Bouzaler.

Bonaparte, C. L. (1835). Prodromus systematis ichthyologiae. Nuovi Annali delle Scienze naturali Bologna Nuovi Annali delle Scienze naturali Bologna, 1(181-196), 272-277.

Bonaparte C.L. (1850). Conspectus systematum. Mastozoölogiae. Ornithologiae. Herpetologiae et Amphibiologiae. Ichthyologiae. E. J. Brill, Lugduni Batavorum.

Bruijn, H. de, Ünay, E., \& Hordijk, K. (2013). A review of the Neogene successions of the Muridae and Dipodidae from Anatoli, with special reference to taxa known from Asia and/or Europe. In X. Wang, L. J. Flynn, \& M. Fortelius (Eds.), Fossil mammals of Asia: Neogene biostratigraphy and chronology. New York: Columbia University Press.

Čerňanský, A., Rage, J.-C., \& Klembara, J. (2015). The Early Miocene squamates of Amöneburg (Germany): the first stages of modern squamates in Europe. Journal of Systematic Palaeontology, 13, 97-128. https://doi.org/10.1080/14772019.2014.897266.

Čerňanský, A., Klembara, J., \& Müller, J. (2016). The new rare record of the Late Oligocene lizards and amphisbaenians from Germany and its impact on our knowledge of the European terminal Palaeogene. Palaeobiodiversity and Palaeoenvironments, 96, 559-587. https:// doi.org/10.1007/s12549-015-0226-8.
Čerňanský, A., Vasilyan, D., Georgalis, G. L., Joniak, P., Mayda, S., \& Klembara, J. (2017). First record of fossil anguines (Squamata; Anguidae) from the Oligocene and Miocene of Turkey. Swiss Journal of Geosciences, 110, 741-751. https://doi.org/10.1007/ s00015-017-0272-5.

Claessens, L. (1996). Miocene reptilia and amphibian faunas of Anatolia: with special emphasis on the anura. Diploma thesis, Utrecht Universtiy.

Claessens, L. (1997). On the herpteofauna of some Neogene Eastern Mediterranean localities and the occurence of Palaeobatrachus and Bufo (Amphibia, Anura) in the Lower Miocene of Turkey. Jounal of Vertebrate Paleontology, 17, 39.

Cope, E. D. (1865). Sketch of the primary groups of Batrachia Salientia. Natural History ReviXew, 5, 97-120.

Cope, E. D. (1887). Zittel's manual of palaeontology. American Naturalist, 21, 427-448.

Cuvier, G. (1816-1817). Le Règne Animal distribué d'après son organisation pour servir de base à l'histoire naturelle des animaux et d'introduction à l'anatomie comparée. Avec Figures, dessinées d'après nature. Contenant Les reptiles, les poissons, les mollusques et les annélides. Paris: Deterville.

Cuvier, G., \& Cloquet, N. (1816). N. genus Barbus. In F. G. Levrault (Ed.), Dictionnaire des sciences naturelles, $2^{\text {nd }}$. Strasbourg: F. G. Levrault.

Cuvier, G., \& Valenciennes, A. (1842). Histoire naturelle des poissons (Vol. 16). Paris: P. Bertrand.

Daudin, F.M. (1803). Histoire naturelle, générale et particulière des reptiles: ouvrage faisant suite à l'histoire naturelle générale et particulieère, composée par Leclerc de Buffon, et rédigée par C. S. Sonnini, membre de plusieurs sociétés savantes. Paris: Dufart.

Delfino, M. (2002). Erpetofaune italiane del Neogene e del Quaternario. Università degli Studi di Modena e Reggio Emilia.

Denk, T., Güner, T. H., Kvaček, Z., \& Bouchal, J. M. (2017). The Early Miocene flora of Güvem (Central Anatolia, Turkey): a window into Early Neogene vegetation and environments in the Eastern Mediterranean. Acta Palaeobotanica, 57, 250. https://doi.org/10. 1515/acpa-2017-0011.

Doadrio, I. (1990). Phylogenetic relationships and classification of western palaearctic species of the genus Barbus (Osterchthyes, Cyprinidae). Aquatic Living Resources, 3, 265-282.

Dubois, A., Grossjean, S., \& Paicheler, J.-C. (2010). Strange tadpoles from the lower Miocene of Turkey: is paedogenesis possible in anurans? Acta Palaeontologica Polonica, 55, 43-55.

Estes, R., \& Hoffstetter, R. (1976). Les Urodèles du Miocène de la GriveSaint-Alban (Isère, France). Bulletin du Muséum National d'Histoire Naturelle, $3^{e}$ Série. Sciences de la Terre, 57, 297-343.

Evans, S.E. (2008). The skull of lizards and tuatara. In C. Gans (Ed.) The skull of Lepidosauria, Volume 20, Morphology H. Society for the Study of Amphibians and Reptiles, Ithaca, pp 1-347.

Fischer, G. (1813). Zoognosia. Tabulis Synopticis Illustrata, in Usum Pralectionum Academice Imperialis Medico-Chirurgica Mosquensis Edita, 3, ${ }^{\text {rd }}$ edn., vol 1. Moscow: Typis Nicolai Sergeidis Vsevolozsky.

Fitzinger, L. (1843). Systema Reptilium. Wien: Fasciculus Primus. Braumüller et Seidel.

Folie, A., Smith, R., \& Smith, T. (2013). New amphisbaenian lizards from the Early Paleogene of Europe and their implications for the early evolution of modern amphisbaenians. Geologica Belgica, 16, 227235.

Frost, D.R. (2014). Amphibian species of the world: an online reference. Version 6.0 (9 January, 2013). Accessed 24.02.20152014.

Garsault, F. A. de, Defehrt, A. J., Prévost, B. L., Duflos, P., Martinet, F. N., \& Geoffroy, É.-F. (1764). Les figures des plantes et animaux d'usage en medecine décrits dans La matiere medicale de Mr. Jacques, Paris: Geoffroy medecin. Chez l'auteur rue St. Dominique porte St. 
Georgalis, G. L., Halaçlar, K., Mayda, S., Kaya, T., \& Ayaz, D. (2018). First fossil find of the Blanus strauchi complex (Amphisbaenia, Blanidae) from the Miocene of Anatolia. Journal of Vertebrate Paleontology, 2234, e1437044. https://doi.org/10.1080/02724634. 2018.1437044.

Gmelin, J.F. (1789). Regnum animale. Caroli a Linne Systema Naturae per regna tri naturae, secundum classes, ordines, genera, species, cum characteribus, differentiis, synonymis, locis. Leipzig: Beer.

Goldfuss, G.A. (1820). Handbuch der Zoologie, Bd. 2. J. L. Schrag, Nürnberg.

Gray, J. E. (1825). A synopsis of the genera of reptiles and Amphibia, with a description of some new species. Ann Philos, London, 10, $193-217$.

Gray, J. E. (1844). Cataloque of tortoises, crocodilians, and amphisbaenians in the collection of the British Museum. Natural History, London: British Museum.

Greven, H., \& Laumeier, I. (1987). A comparative SEM-Study on the Teeth on 10 Anuran Species. Anatomischer Anzeiger, 164, 103-116.

Greven, H., \& Ritz, A. (2008/2009). Tricuspid teeth in Anura (Amphibia). Acta Biologica Benrodis, 15, 67-74.

Heckel, J.J. (1843). Abblidungen und Beschreibungen der Fische Syriens, nebst einer neuen Classification und Characteristik sämmtlicher Gattungen der Cyprinen. Stuttgart: E. Schweizerbart'sche Verlagsbuchhandlung.

Hoek Ostende, L. W. van den, Gardner, J. D., Bennekom, L. van, Alcicek M. C., Murray A., Wesselingh, F. P., Alçiçek H., Tesakov, A. (2015). Ericek, a new Pliocene vertebrate locality in the Cameli Basin (southwestern Anatolia, Turkey). In L. W. van den Hoek Ostende, P. Peláez-Campomanes, W. Wessels (Eds.) Old worlds, new ideas. A tribute to Albert van der Meulen. Palaeobiodiversity and Palaeoenvironments 95(3), 305-320. doi: https://doi.org/10.1007/ s12549-015-0202-3.

Hoffstetter, R., \& Gasc, J.-P. (1969). Vertebrae and rips of modern reptiles. In C. Gans (Ed.), Morphology A, biology of the reptilia (pp. 201-310). London, New York: Academic Press.

Hoffstetter, R., \& Rage, J.-C. (1972). Les Erycinae fossiles de France (Serpentes, Boidae) Compréhension et histoire de la sous-famille. Annales de Paleontologie 58, 81-124.

Hooker, J.J. (2010). The "Grande Coupure" in the Hampshire Basin, UK: taxonomy and stratigraphy of the mammals on either side of this major Palaeogene faunal turnover. In J.E. Whittaker, M.B. Hart MB (Eds.) Micropalaeontology, sedimentary environments and stratigraphy: a tribute to Dennis Curry (1912-2001) (pp 147-215). London: Geological Society.

Hossini, S., \& Rage, J.-C. (2000). Palaeobatrachid frogs from the earliest Miocene (Agenian) of France, with description of a new species. Geobios, 33, 223-231. https://doi.org/10.1016/s0016-6995(00)80019-4.

Ivanov, M., Vasilyan, D., Böhme, M., \& Zazhigin, V. S. (2018). Miocene snakes from northeastern Kazakhstan: new data on the evolution of snake assemblages in Siberia. Historical Biology, 183, 1-20. https:// doi.org/10.1080/08912963.2018.1446086.

Kamermans, M., \& Vences, M. (2009). Terminal phalanges in ranoid frogs, morphological diversity and evolutionary correlation with climbing habits. Alytes, 26, 117-152.

Kaymekci N. (2000). Tectono-stratigraphical evolution of the Çankırı Basin (Central Anatolia, Turkey). Geologica Ultraiectina. Mededelingen van de Faculteit Aardwetenschappen Universteit Utrecht, vol 190. Universiteit Utrecht, Utrecht.

Kearney, M. (2003). Systematics of the Amphisbaenia (Lepidosauria: Squamata) based on morphological evidence from recent and fossil forms. Herpetological Monographs, 17, 1-74.

Klembara, J., \& Rummel, M. (2018). New material of Ophisaurus, Anguis and Pseudopus (Squamata, Anguidae, Anguinae) from the Miocene of the Czech Republic and Germany and systematic revision and palaeobiogeography of the Cenozoic Anguinae.
Geological Magazine, 155, 20-44. https://doi.org/10.1017/ S0016756816000753.

Klembara, J., Böhme, M., \& Rummel, M. (2010). Revision of the anguine lizard Pseudopus laurillardi (Squamata, Anguidae) from the Miocene of Europe, with comments on paleoecology. Journal of Paleontology, 8, 159-196.

Klembara, J., Hain, M., \& Dobiašová, K. (2014). Comparative anatomy of the lower jaw and dentition of Pseudopus apodus and the interrelationships of species of subfamily Anguinae (Anguimorpha, Anguidae). The Anatomical Record, 297, 516-544. https://doi.org/ 10.1002/ar.22854.

Kosma, R. (2004). The dentition of recent and fossil scincomorphan lizards (Lacertilia, Squamata)-systematics, functional morphology, palaeoecology. Fachbereich Geowissenschaften und Geographie, Universität Hannover.

Kottelat, M., \& Freyhof, J. (2007). Handbook of European freshwater fishes, $B d$. 13. Berlin: Publications Kottelat.

Krijgsman, W. (2003). Magnetostratigraphic dating of the Çandır fossil locality (Middle Miocene, Turkey). Courier Forschungsinstitut Senckenberg, 240, 41-49.

Krijgsman, W., Duermeijer, C. E., Langereis, C. G., Bruijn, H., de Saraç, G., \& Andriessenm Paul, A. M. (1996). Magnetic polarity stratigraphy of Late Oligocene to Middle Miocene mammal-bearing continental deposits in Central Anatolia (Turkey). Newsletters on Stratigraphy, 34, 13-29.

Laurenti, J. N. (1768). Specimen medicum, exhibens synopsin reptilium emendatum cum experimentis circa venena et antidota Reptilium Austriacorum. Viennae: Typ Joan Thom nob de Trattnern.

Legendre, S. (1989). Les communantés de mammifères du Paléogène (Eocène supéreur et Oligocène) d'Europe Occidentale: structures, milieux et évolution. Münchner Geowissenschaftliche Abhandlungen (A), 116, 1-110.

Linnaeus, C. (1758). Systema naturae per regna tria naturae, secundum classes, ordines, genera, species, cum characteribus, differentiis, synonymis, locis, Editio decima, reformata. Stockholm: L. Salvi.

Marković, Z., Wessels, W., Weerd, Andrew, A. van de, \& Bruijn, H. de (2018). On a new diatomyid (Rodentia, Mammalia) from the Paleogene of south-east Serbia, the first record of the family in Europe. Palaeobiodiversity and Palaeoenvironments 98, 459-469. doi: https://doi.org/10.1007/s12549-017-0301-4.

Maus, M., \& Wuttke, M. (2004). The ontogenetic development of Pelobates cf. decheni tadpoles from the Upper Oligocene of Enspel (Westerwald/Germany). Neues Jahrbuch für Geologie und Paläontologie, Abhandlungen, 232, 215-203.

Merrem, B. (1820). Versuch eines Systems der Amphibien. Marburg: Johann Christian Krieger.

Meyer, H. von (1843). Mittheilung an Professor Bronn gerichtet. Neues Jahrbuch für Mineralogie, Geognosie, Geologie und Petrefaktenkunde, 1843, 579-590.

Müller, J. (1996). Eine neue Art der Echten Eidechsen (Reptilia: Lecertilia: Lacertidae) aus dem Unteren Miozän von Poncenat, Frankreich. Mainzer Geowissenschaftliche Mitteilungen, 25, 79-88.

Oppel, M. (1811). Die Ordnungen, Familien und Gattungen der Reptilien als Prodrom einer Naturgeschichte derselben. München: Joseph Lindauer.

Paicheler, J.-C. (1978). Volcanic paleoenvironment and examples of sedimentary incidences at Tertiary Beșkonak Lake (Northern AnatoliaTurkey). Bulletin of the Geological Society of Turkey, 21, 11-25.

Paicheler, J.-C., Broin, F., de Gaudant, J., Mourer-Chauviré, C., Rage, J.C., \& Vergnaud-Grazzini, C. (1978). Le bassin lacustrine Miocène de Bes-Konak (Anatolie-Turquie): Géologie et intruduction a la paléontologie des vertébrés. Geobios, 11, 43-65.

Rafinesque, C. S. (1815). Analyse de Nature, ou Tableau de l'Universe et des Corps Organisés. Palermo: Jean Barravecchia. 
Rage J.-C. (1984). Serpentes. Handbuch der PaläoherpetologyEncyclopedia of Paleoherpetology, vol 11. Stuttgart, New York: Gustav Fischer.

Rage, J.-C. (2012). Amphibians and squamates in the Eocene of Europe: what do they tell us? In T. Lehmann, \& S.F.K. Schaal (Eds.) Messel and the terrestrial Eocene-proceedings of the 22nd Senckenberg Conference. Palaeobiodiversity and Palaeoenvironments 92(4), 445-457. doi: https://doi.org/10.1007/s12549-012-0087-3.

Rage, J.-C., \& Hossini, S. (2000). Les Amphibiens du Miocène moyen de Sansan. Mémoires du Muséum national d'histoire naturelle, 183, 177-217.

Roček, Z. (1981). Cranial anatomy of frogs of the family Pelobatidae Stannius, 1856, with outlines of their phylogeny and systematics. Acta Universitatis Carolinae - Biologica, 1980, 1-164.

Roček, Z. (1984). Lizards (Reptili: Sauria) from the Lower Miocene locality Dolnice (Bohemia, Czechoslovakia). Řada matematických a prirodnich vĕd, 94, 4-69.

Roček, Z. (1994). Taxonomy and distribution of Tertiary discoglossids (Anura) of the genus Latonia V. Meyer, 1843. Geobios, 27, 717-751.

Roček, Z. (2013). Mesozoic and Tertiary Anura of Laurasia. In J.D. Gardner; R.L. Nydam (Eds.) Mesozoic and Cenozoic Lissamphibian and Squamate assemblages of Laurasia. Palaeobiodiversity and Palaeoenvironments, 93(4), 397-439. https://doi.org/10.1007/s12549-013-0131-y.

Roček Z., \& Wuttke M. (2010).Amphibia of Enspel (Late Oligocene, Germany). In M. Wuttke, D. Uhl, \& T. Schindler (Eds.) FossilLagerstätte Enspel-exceptional preservation in an Upper Oligocene maar. Palaeobiodiversity and Palaeoenvironments 90(1), 321-340. doi: https://doi.org/10.1007/s12549-010-0042-0

Roček, Z., Wuttke, M., Gardner, J., \& Singh Bhullar, B.-A. (2014). The Euro-American genus Eopelobates, and a re-definition of the family Pelobatidae (Amphibia, Anura). Palaeobiodiversity and Palaeoenvironments, 94, 529-567. https://doi.org/10.1007/s12549014-0169-5.

Rögl, F. (1999). Mediterranian and Paratethys. Facts and hypotheses of an Oligocene to Miocene paleogeography (short overview). Geologica Carpathica, 50, 339-349.

Rössner, G., \& Heissig, K. (Eds.) (1999). The Miocene Land Mammals of Europe. München: Verlag Dr. Friedrich Pfeil.

Rückert-Ülkümen, N. (1998). Cyprinidae (Pisces) aus dem Jungtertiär von Alpagut-Dodurga bei Çorum (Mittelanatolien, Türkei). Mitteilungen der Bayerischen Staatssammlung für Paläontologie und Historische Geologie, 38, 167-181.

Russell, A. P., \& Bauer, A. M. (2008). The appendicular locomotor apparatus of Sphenodon and normal-limbed squamtes. In C. Gans, A. S. Gaunt, \& A. Kraig (Eds.), The skull and appendicular locomotor apparatus of Lepidosauria, Volume 21, Morphology 1 (pp. 1-465). Ithaca: Society for the Study of Amphibians and Reptiles.

Rutte, E. (1962). Schlundzähne von Süßwasserfischen. Palaeontographica Abteilung A, 120, 165-212.

Sanchíz, B. (1998). Salientia. Handbuch der Paläoherpetologie. München: Verlag Dr. Friedrich Pfeil.

Schleich, H.-H. (1994). Fossile Schildkröten- und Krokodilreste aus dem Tertiär Thrakiens (W-Türkei). Courier Forschungsinstitut Senckenberg, 17, 137-151.

Schultz, O. (2004). Die Fischreste aus dem Unter-Pannonium (OberMiozän) on Mataschen, Steiermark (Österreich). Joannea Geologie und Paläontologie, 5, 231-256.

Scopoli, G. A. (1777). Introductio ad historiam naturalem, sistens genera lapidum, plantarum et animalium hactenus detecta, caracteribus essentialibus donata, in tribus divisa, subinde ad leges naturae. Prague: Apud Wolfgangum Gerle.

Sen, S., Antoine, P.-O., Varol, B., Ayyildiz, T., \& Sözeri, K. (2011). Giant rhinoceros Paraceratherium and other vertebrates from Oligocene and Middle Miocene deposits of the Kağıman-Tuzluca Basin,
Eastern Turkey. Naturwissenschaften, 98, 407-423. https://doi.org/ 10.1007/s00114-011-0786-z.

Syromyatnikova, E. (2018). Palaeobatrachid frog from the Late Miocene of Northern Caucasus, Russia. Palaeontologia Electronica, 21.2.30A: 1-16. https://doi.org/10.26879/861.

Szyndlar, Z. (1987). Snakes from the Lower Miocene locality of Dolnice (Czechoslovakia). Journal of Vertebrate Paleontology, 7, 55-71.

Szyndlar, Z. (1991). A review of Neogene and Quaternary snakes of central and eastern Europe. Part 1: Scolecophidia, Boidae, Colubrinae. Estudios Geológicos, 47, 103-126.

Szyndlar, Z., \& Hoşgör, I. (2013). Bavarioboa sp. (Serpentes, Boidae) from the Oligocene/Miocene of eastern Turkey with comments on connections between European and Asiatic snake faunas. Acta Palaeontologica Polonica, 57, 667-671.

Szyndlar, Z., \& Schleich, H.-H. (1993). Description of Miocene Snakes from Petersbuch 2 with Comments on the Lower and Middle Miocene Ophidian Faunas of Southern Germany. Stuttgarter Beiträge zur Naturkunde Serie B (Geologie und Paläontologie), $192,1-47$.

Tesakov, A. S., Titov, V. V., Simakova, A. N., Frolov, P. D., Syromyatnikova, E. V., Kurshkov, S. V., Volkova, N. V., Trikhunkov, Y. I., Sotnikova, M. V., Kruskop, S. V., Zelenkov, N. V., Tesakova, E. M., \& Palatov, D. M. (2017). Late Miocene (Early Turolian) vertebrate faunas and associated biotic record of the Northern Caucasus: Geology, palaeoenvironment, biochronology. Fossil Imprint, 73, 383-444.

Tihen, J. A. (1962). A review of New World fossil bufonids. The American Midland Naturalist, 68, 1-50.

Vasilyan, D. (in press). Fish, amphibian and reptilian assemblage from the Middle Miocene locality Gračanica-Bugojno palaeolake, Bosnia and Herzegovina. In U.B. Göhlich \& O. Mandic (Eds.) The drowning swamp of Gračanica (Bosnia-Herzegovina)-a diversity hotspot from the middle Miocene in the Bugojno Basin. Palaeobiodiversity and Palaeoenvironments. doi: https://doi.org/10.1007/s12549-01900381-8.

Vasilyan, D. (2018). Eocene Western European endemic genus Thaumastosaurus: new insights into the question "are the Ranidae known prior to the Oligocene?". PeerJ, 6, e5511. https://doi.org/10. 7717/peerj.5511.

Vasilyan, D., Böhme, M., \& Klembara, J. (2016). First record of fossil Ophisaurus (Anguimorpha, Anguidae, Anguinae) in Asia. Journal of Vertebrate Paleontology, 1-6. https://doi.org/10.1080/02724634. 2016.1219739.

Vasilyan, D., Zazhigin, V. S., \& Böhme, M. (2017). Neogene amphibians and reptiles (Caudata, Anura, Gekkota, Lacertilia, Testudines) from south of Western Siberia, Russia and Northeastern Kazakhstan. PeerJ, 5, e3025. https://doi.org/10.7717/peerj.3025.

Venczel, M. (2006). Lizards from the Late Miocene of Polgárdi (WHungary). Nymphaea, Folia naturae Bihariae, 33, 25-38.

Villa, A. (2018). Neogene and Quaternary Neogene and Quaternary palaeodiversity of the European lizards (Reptilia, Squamata). Università degli Studi di Torino.

Wang, X., Flynn, L. J., \& Fortelius, M. (Eds.). (2013). Fossil mammals of Asia: Neogene biostratigraphy and chronology. New York: Columbia University Press.

Wang, Y., Roček, Z., \& Dong, L. (2017). A new pelobatoid frog from the lower Eocene of southern China. Palaeobiodiversity and Palaeoenvironments, 98(2), 225-242.

Wassersug, R. J., \& Wake, D. B. (1995). Fossil tadpoles from the Miocene of Turkey. Alytes, 12, 145-157.

Wilson, M., Tankut, A., \& Guleç, N. (1997). Tertiary volcanism of the Galatia province, north-west Central Anatolia, Turkey. Lithos, 42, 105-121. https://doi.org/10.1016/S0024-4937(97)00039-X.

Winfield, I. J., \& Nelson, J. S. (Eds.). (1991). Cyprinid fishes, systematics, biology and exploitation. London, New York, Tokyo, Melbourn, Madras: Chapman \& Hall. 
Wuttke, M., Přikryl, T., Ratnikov, V. Y., Dvořák, Z., \& Roček, Z. (2012). Generic diversity and distributional dynamics of the Palaeobatrachidae (Amphibia: Anura). Palaeobiodiversity and Palaeoenvironments, 92(3), 367-395. https://doi.org/10.1007/ s12549-012-0071-y.

Yang, L., Sado, T., Vincent, H. M., Pasco-Viel, E., Arunachalam, M., Li, J., Wang, X., Freyhof, J., Saitoh, K., Simons, A. M., Miya, M., He, S., \& Mayden, R. L. (2015). Phylogeny and polyploidy: resolving the classification of cyprinine fishes (Teleostei: Cypriniformes). Molecular Phylogenetics and Evolution, 85, 97-116. https://doi. org/10.1016/j.ympev.2015.01.014.

Yavuz-Iș1k, N. (2008). Vegetational and climatic investigations in the Early Miocene lacustrine deposits of the Güvem Basin (Galatean
Volcanic Province), NW Central Anatolia, Turkey. Review of Palaeobotany and Palynology, 150, 130-139. https://doi.org/10. 1016/j.revpalbo.2008.02.001.

Zachos, J., Pagani, M., Sloan, L., Thomas, E., \& Billups, K. (2001). Trends, rhythms, and aberrations in global climate $65 \mathrm{Ma}$ to present. Science, 292, 686-693. https://doi.org/10.1126/science.1059412.

Zerova, G. A. (1989). First find of the fossil erycin of the genus Albaneryx (Reptili, Boidae) in USSR. Vestnik Zoologii, 23, 31-35.

Publisher's note Springer Nature remains neutral with regard to jurisdictional claims in published maps and institutional affiliations. 